\title{
Low-Cost Unmanned Aerial Multispectral Imagery for Siltation Monitoring in Reservoirs
}

\author{
Diogo Olivetti ${ }^{1, *}$, Henrique Roig ${ }^{1}$, Jean-Michel Martinez ${ }^{2}$, , Henrique Borges ${ }^{1}$, \\ Alexandre Ferreira ${ }^{1}$, Raphael Casari ${ }^{1}$, Leandro Salles ${ }^{1}$ and Edio Malta ${ }^{1}$ \\ 1 Institute of Geosciences, University of Brasília, Campus Darcy Ribeiro, ICC-Ala Central-CEP 70, \\ Brasília 910-900, Brazil; roig@unb.br (H.R.); 180044443@aluno.unb.br (H.B.); \\ alexandre.ferreira@terrasense.com.br (A.F.); 180133799@aluno.unb.br (R.C.); 150168853@aluno.unb.br (L.S.); \\ edio.malta@ana.gov.br (E.M.) \\ 2 Géosciences Environment Toulouse (GET), UMR5563, Institut de Recherche pour le Développement (IRD), \\ Centre National de la Recherche Scientifique (CNRS), Université Toulouse 3, 14 Avenue Edouard Belin, \\ 31400 Toulouse, France; jean-michel.martinez@ird.fr \\ * Correspondence: 150028351@aluno.unb.br
}

Received: 1 May 2020; Accepted: 26 May 2020; Published: 8 June 2020

\begin{abstract}
The recent and continuous development of unmanned aerial vehicles (UAV) and small cameras with different spectral resolutions and imaging systems promotes new remote sensing platforms that can supply ultra-high spatial and temporal resolution, filling the gap between ground-based surveys and orbital sensors. This work aimed to monitor siltation in two large rural and urban reservoirs by recording water color variations within a savanna biome in the central region of Brazil using a low cost and very light unmanned platform. Airborne surveys were conducted using a Parrot Sequoia camera $(\sim 0.15 \mathrm{~kg})$ onboard a DJI Phantom 4 UAV $(\sim 1.4 \mathrm{~kg})$ during dry and rainy seasons over inlet areas of both reservoirs. Field measurements of total suspended solids (TSS) and water clarity were made jointly with the airborne survey campaigns. Field hyperspectral radiometry data were also collected during two field surveys. Bio-optical models for TSS were tested for all spectral bands of the Sequoia camera. The near-infrared single band was found to perform the best ( $R^{2}$ : 0.94; RMSE: $7.8 \mathrm{mg} \mathrm{L}^{-1}$ ) for a $0-180 \mathrm{mg} \mathrm{L}^{-1}$ TSS range and was used to produce time series of TSS concentration maps of the study areas. This flexible platform enabled monitoring of the increase of TSS concentration at a $\sim 13 \mathrm{~cm}$ spatial resolution in urban and rural drainages in the rainy season. Aerial surveys allowed us to map TSS load fluctuations in a 1 week period during which no satellite images were available due to continuous cloud coverage in the rainy season. This work demonstrates that a low-cost configuration allows dense TSS monitoring at the inlet areas of reservoirs and thus enables mapping of the sources of sediment inputs, supporting the definition of mitigation plans to limit the siltation process.
\end{abstract}

Keywords: water quality; inland water; total suspended solids; remote sensing; UAV; remotely piloted aircraft; drone; Parrot Sequoia; urban drainage, reservoir

\section{Introduction}

Conventional monitoring of water quality in lakes and reservoirs relies on frequently conducted pointwise limnologic surveys but usually fails to capture the spatial variability of the underlying processes [1]. Remote sensing is increasingly used to fill gaps in conventional monitoring thanks to its capacity to acquire spatialized data and to the ability to generate long time series by combining information from different sensors [2,3]. Remote sensing techniques over inland waters are based on the analysis of water optical properties, such as the apparent and inherent optical properties, and of the 
optically active components (OAC) — total suspended solids (TSS), chlorophyll- $a$ (Chl- $a$ ), and colored dissolved organic matter (CDOM) — by applications of either empirical, semi-empirical, semi-analytical, quasi-analytical, or analytical bio-optical models [4].

Despite advances in the use of remote sensing, there are a series of limitations in the application of orbital images for inland water quality monitoring:

(1) No spaceborne platforms are delivering low-cost high spatial, temporal, and spectral resolutions at the same time [5].

(2) Atmospheric corrections of orbital images are often less accurate over inland waters than oceanic waters [6].

(3) Visible passive spaceborne sensors are vulnerable to cloud coverage, especially during the rainy season when the water and sediment discharge to lakes and reservoirs is maximum.

Airborne imagery platforms can overcome some of the limitations of orbital platforms. Manned aerial missions have been applied for inland water quality monitoring, seeking more detailed mapping of the OAC with high precision [7]. However, this resource has high operational costs and, when surveys are realized at a high flight altitude, atmospheric corrections cannot be overlooked [8,9].

Recent advances and developments in robotics and sensor technology have generated a new and low-cost airborne remote sensing platform type with the integration of unmanned aerial vehicles (UAV), small spectral cameras (with different spectral resolutions and imagery systems), associated software based in computer vision, and photogrammetry that can provide products with ultra-high temporal and spatial resolutions [10]. With the development of new methods and applications of UAVs for water quality analysis and monitoring, the user of this data can obtain results with much less effort than conventional fieldwork [11]. A review of the recent literature about water quality and UAV in the Web of Science ${ }^{\mathrm{TM}}$ Core Collection database provides an interesting perspective, although is it not the main area of application among UAV-based studies [12].

Some work has already applied this technology for inland water quality monitoring in small reservoirs and rivers ( $<70$ ha) with distinct methodologies. Ref. [13] used an infrared camera for water quality monitoring using a fuzzy logic model in a small reservoir in Japan. Ref. [14,15] applied a Canon Powershot S110 NIR camera for water quality monitoring in small lakes in Taiwan using a matching pixel-by-pixel model. Ref. [16] mapped TSS concentrations in a small lake and river using a Headwall push-broom hyperspectral camera applying a particle swarm optimization algorithm in a Chinese reservoir.

Although light UAV and small cameras comprise a new and promising remote sensing platform, there are limitations in their applications for water quality monitoring in large reservoirs, such as insufficient flight autonomy to cover large areas. However, the inlet areas of the reservoirs can be easily covered by UAV surveys and are of fundamental interest because these are areas where water and sediment flow velocity decrease from a riverine flow to a lake flow. These areas are relevant for water quality monitoring due to the intense deposition of suspended matter, including inorganic material, nutrients, or heavy metals. Medium- to high-resolution spaceborne sensors, such as Sentinel-2 or Landsat-8, can hardly monitor such critical areas, especially during the rainy season when cloud coverage is almost permanent.

The objective of this work was to develop a low-cost UAV-based mapping method, easily reproducible, relying on a lightweight and flexible unmanned multispectral airborne platform for TSS monitoring with a very high spatial resolution suitable for both urban and rural reservoirs. We used water quality samples and field radiometry to fully assess the accuracy of the method, analyzing how the selection of a radiometric model affects the final mapping accuracy.

\section{Materials and Methods}

The methodology developed in this work was carried out in the following stages: 
(1) Planning and execution of unmanned airborne surveys with the Sequoia camera over the study areas;

(2) Image processing to generate at-sensor reflectance orthomosaics;

(3) In situ data acquisition concurrently with flights;

(4) Development, statistical analysis, and selection of bio-optical models based on the in situ TSS data and the at-sensor reflectance pixels of orthomosaics;

(5) Application of the most robust model (with the best statistical performance) for the TSS mapping;

(6) TSS mapping accuracy assessment.

Geoprocessing tools were used to extract the at-sensor reflectance and TSS estimated pixel values. These tools were also used to apply the most robust bio-optical model for TSS mapping over the study areas. Figure 1 shows the flowchart of the methodological procedures.

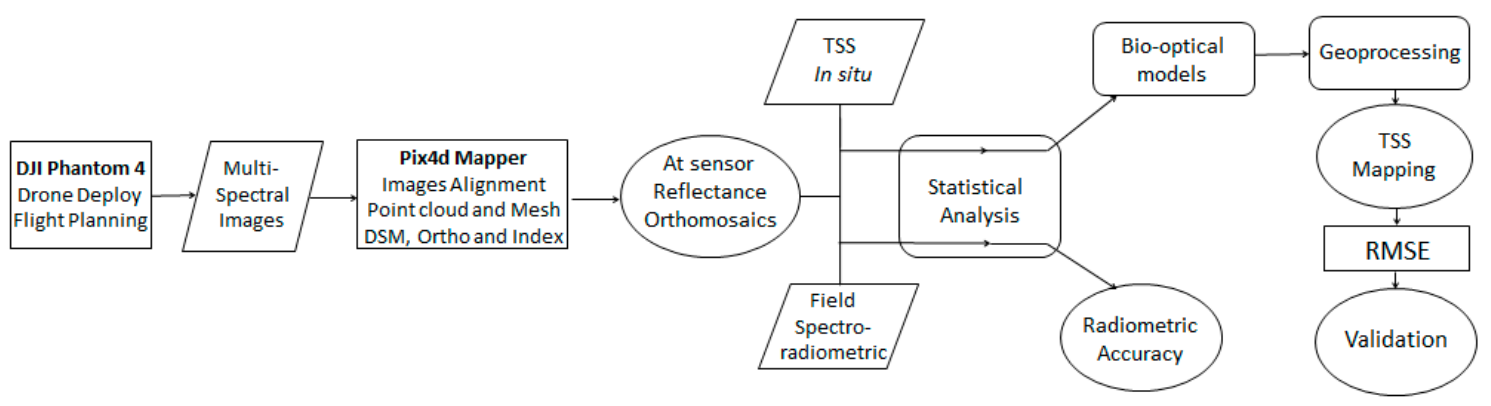

Figure 1. Flowchart of methodological procedures for TSS mapping, validation, and radiometric accuracy analysis of the unmanned multispectral platform.

Regression analysis was used to create and to evaluate the performance of the bio-optical models. Root mean square error (RMSE, Equation (1)) was employed to quantify the accuracy of the estimated TSS values relative to the in situ TSS data.

$$
\text { RMSE }=\sqrt{\sum_{i=1}^{n} \frac{\left(X^{\prime}-X\right)^{2}}{n}}
$$

where $X^{\prime}$ is the estimated value, $X$ is the measured value, and $n$ is the number of samples.

\subsection{Study Area}

Two reservoirs localized in the central region of Brazil within a savanna biome were studied: the Paranoá and the Corumbá IV reservoirs (Figure 2).

The Paranoá reservoir (Figure 2C) is a medium urban reservoir with an area of $38 \mathrm{~km}^{2}$ [17] that was created by the damming of the Bananal (Figure 2C1), Torto (Figure 2C2), Riacho Fundo (Figure 2C3), and Gama (Figure 2C4) rivers during the construction of Brasília (Brazil's capital) in the 1950s and 1960s. It is an important resource for leisure, electric energy, dilution of treated sewage, urban drainage reception, and water supply. The Corumbá IV reservoir is a large rural reservoir with an area of $178 \mathrm{~km}^{2}$ [18] that was created by the damming of the Alagado (Figure 2D1), Descoberto (Figure 2D2), Areias (Figure 2D3), Corumbá (Figure 2D4), and Antas (Figure 2D5) rivers in the 2000s. The Corumbá IV reservoir is used for hydropower, water supply, fish farming, irrigation, and recreation. The rainy season extends from October to March and the dry season extends from April to September.

The experimental area in the Paranoa reservoir was the inlet of the Bananal River, which delivers a high sediment discharge, mainly during the rainy season, originating from urban drainage system outfall (Figure 3). The experimental area in Corumbá IV was the inlet of the Areias River (Figure 4), which also delivers sediment discharge during the rainy season. Both reservoirs are known to suffer from siltation, eutrophication processes, and other environmental issues. They are used to supply 
drinking water to the city of Brasília and monitoring of water quality is considered to be of critical interest for public health.

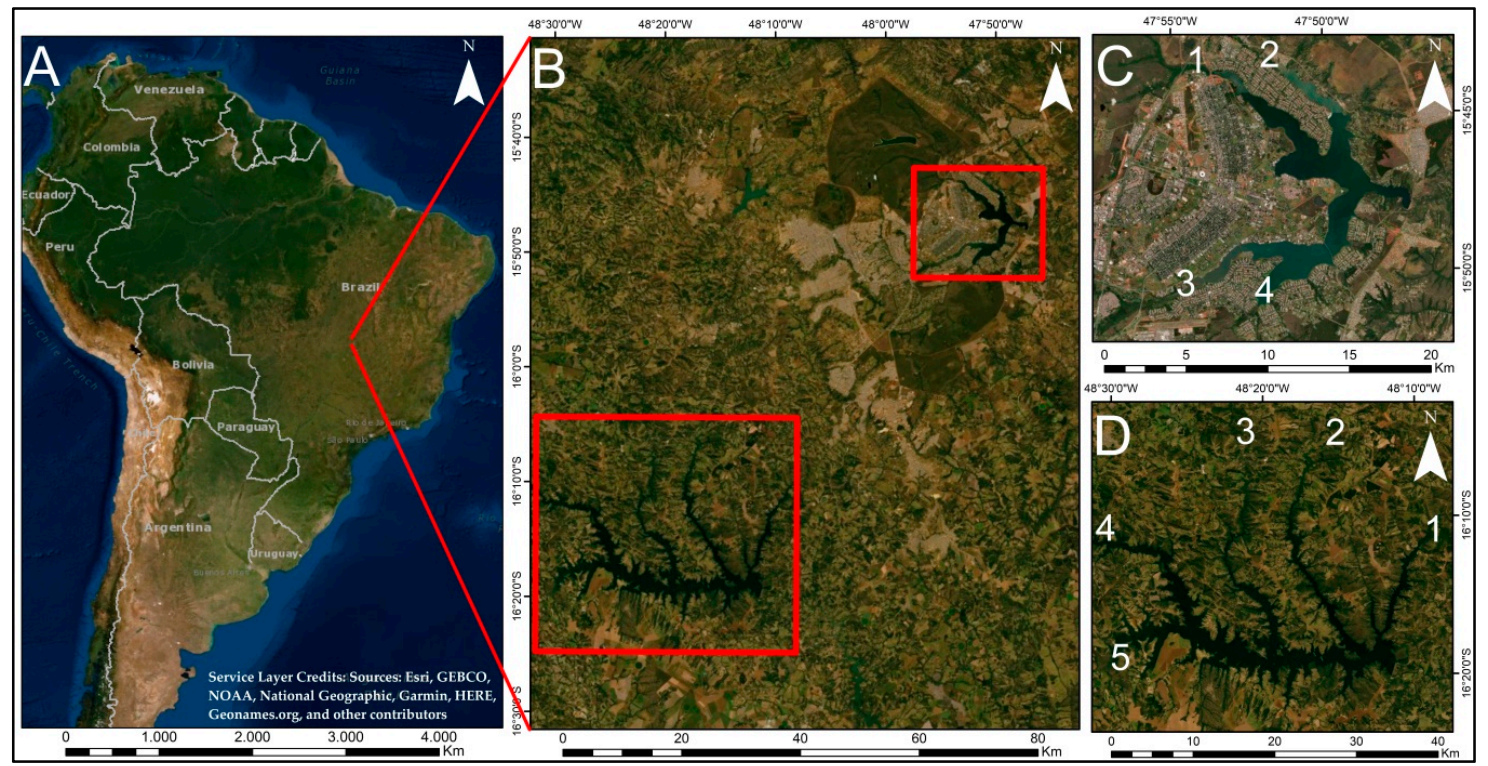

Figure 2. Location map of the urban (Paranoá-C) and rural (Corumbá IV-D) reservoirs highlighting its tributaries rivers (1: Bananal, 2: Torto, 3: Riacho Fundo, and 4: Gama in Paranoá/1: Alagado, 2: Descoberto, 3: Areias, 4: Corumbá, and 5: Antas in Corumbá IV) in the central region of Brazil (A) within a savanna biome (B).

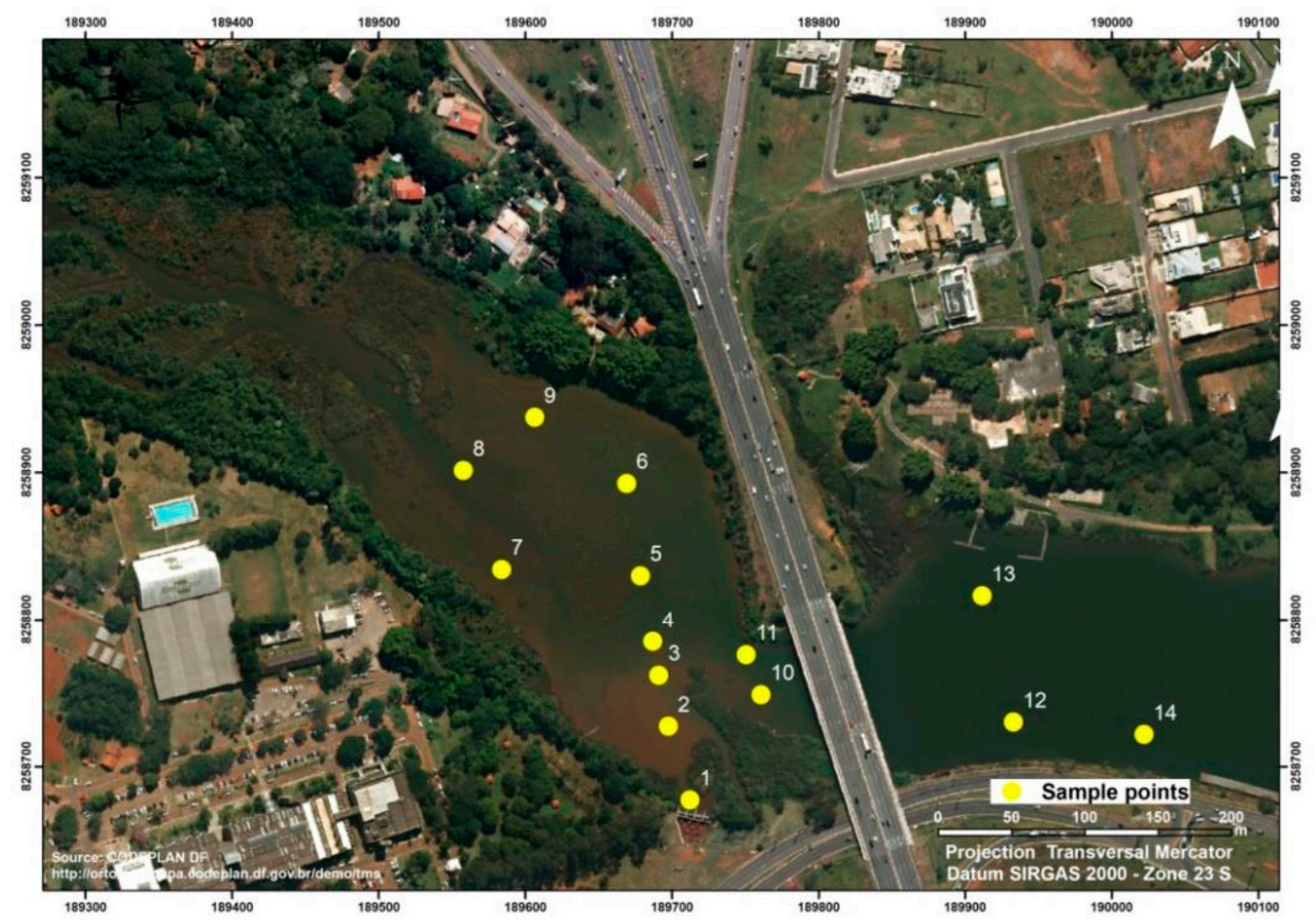

Figure 3. Location map of the inlet area between the Bananal River and the Paranoá reservoir highlighting the in situ data sample points. 


\subsection{Unmanned Multispectral Platform: Camera, UAV, Flight Planning, and Data Processing}

\subsubsection{Multispectral Platform}

Parrot Sequoia is a small and lightweight camera that can be deployed from several UAV models. Although this camera was developed for agricultural applications, in this study it was tested for inland water quality monitoring. The camera has four spectral bands in the visible/near-infrared (NIR) spectrum: green, red, red-edge, and NIR. The camera has a 1.2-megapixel resolution for each of the multispectral bands and an RGB sensor that captures simultaneous true-color images with 16 megapixel resolution (Table 1). Sequoia has an accessory piece (Figure 5a) that contains a GPS/IMU/magnetometer system and a cosine sensor that has four filters to measure the downwelling irradiance for the same spectral ranges as the Sequoia camera multispectral bands registering upwelling radiance. These ancillary data facilitate orthomosaic generation from the spectral images with at-sensor reflectance pixel values [19,20].

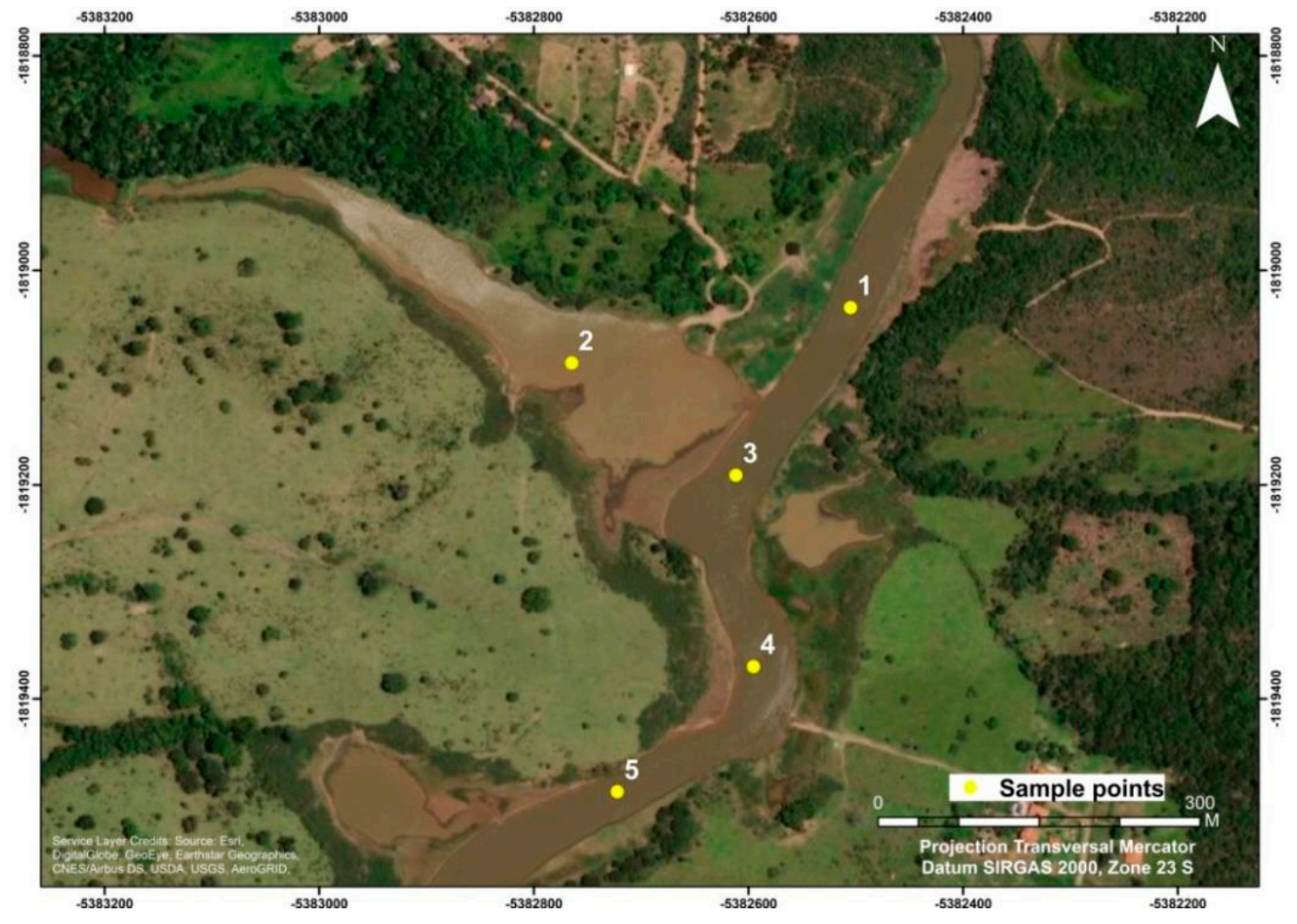

Figure 4. Location map of the inlet area between the Areias River and the Corumbá IV reservoir highlighting the in situ data sample points.

Table 1. Sequoia camera and specifications of the multispectral bands and RGB lens.

\begin{tabular}{ccccc}
\hline Lens & Bandwidth * & $\begin{array}{c}\text { Central } \\
\text { Wavelength }\end{array}$ & Resolution & $\begin{array}{c}\text { Acquisition } \\
\text { System }\end{array}$ \\
\hline GREEN & $40 \mathrm{~nm}$ & $550 \mathrm{~nm}$ & $1.2 \mathrm{Mpx}$ & Global Shutter \\
RED & $40 \mathrm{~nm}$ & $660 \mathrm{~nm}$ & $1.2 \mathrm{Mpx}$ & Global Shutter \\
RED-EDGE & $10 \mathrm{~nm}$ & $735 \mathrm{~nm}$ & $1.2 \mathrm{Mpx}$ & Global Shutter \\
NIR & $40 \mathrm{~nm}$ & $790 \mathrm{~nm}$ & $1.2 \mathrm{Mpx}$ & Global Shutter \\
RGB & & & $16 \mathrm{Mpx}$ & Rolling Shutter \\
\hline
\end{tabular}

*: The spectral characteristics are equivalent between the camera and the cosine sensor. 
(a)

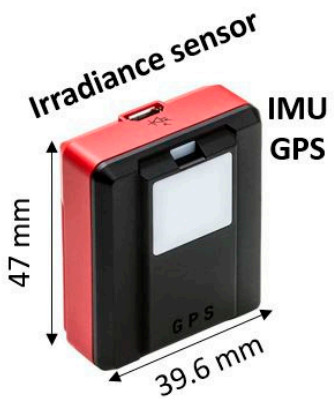

(b)

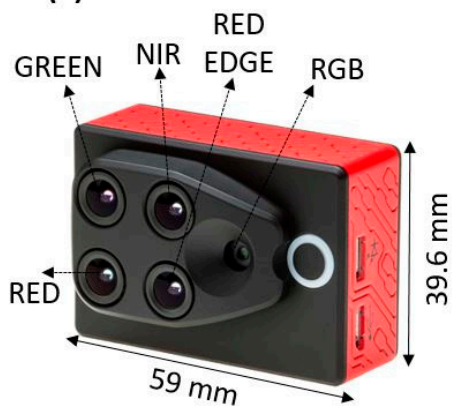

(c)

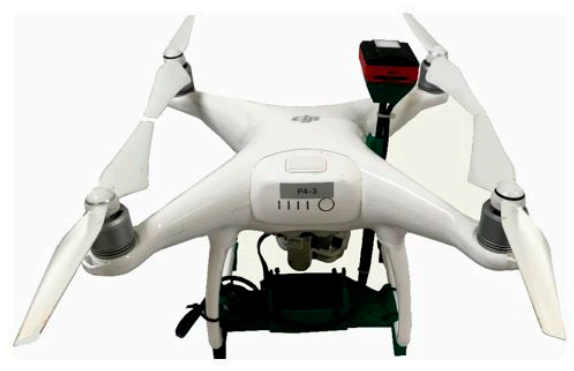

Figure 5. Lightweight unmanned platform highlighting the Sequoia's accessory piece (a), the Sequoia

(b), and its package placed in the 3D mount onboard the DJI Phantom 4 UAV (c).

\subsubsection{Flight Planning}

A routine consisting of six steps was adopted for the airborne surveys: area selection, safety analysis, flight planning, equipment preparation, equipment checking in the field, and data collection. The choice of the area was made considering the limitations that are inherent to the use of UAV such as operational flight altitude and flight time. For security reasons, all flights were monitored by a telemetry system, which sends information about the flight such as energy consumption and battery conditions in real-time. Moreover, the flights were regulated and authorized with the Brazilian National Civil Aviation Agency.

Autonomous aerial flights (Figure 6) were performed using the Drone Deploy mission planning software from $120 \mathrm{~m}$ AGL (above ground level) altitude with 80\% frontal and 65\% lateral overlap to ensure a good alignment of the images and to generate orthomosaics with a ground sample distance (GSD) of $13 \mathrm{~cm} /$ pixel. Nine flight campaigns were carried during dry and rainy seasons (Table 2), sometimes just after rainfall events, from March to December 2018. All the flights were performed with high solar zenith angle conditions to avoid sun glint effects [21].

(a)

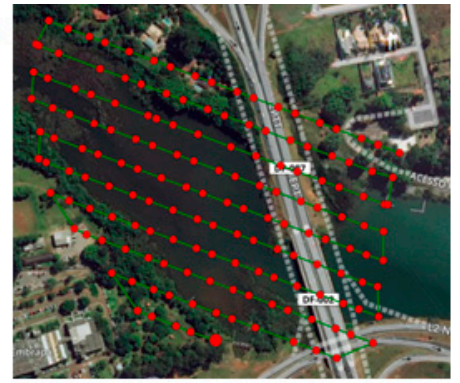

Flight Planning: Drone Deploy

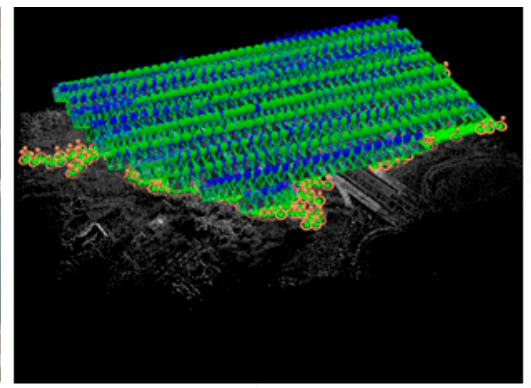

Image processing: Pix4d Mapper

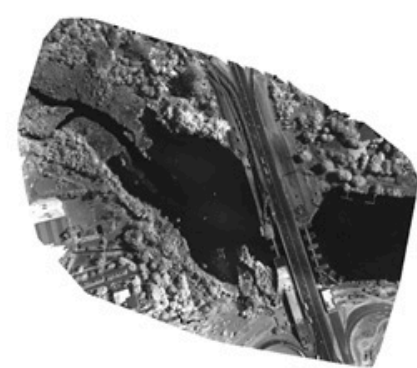

Orthomosaic
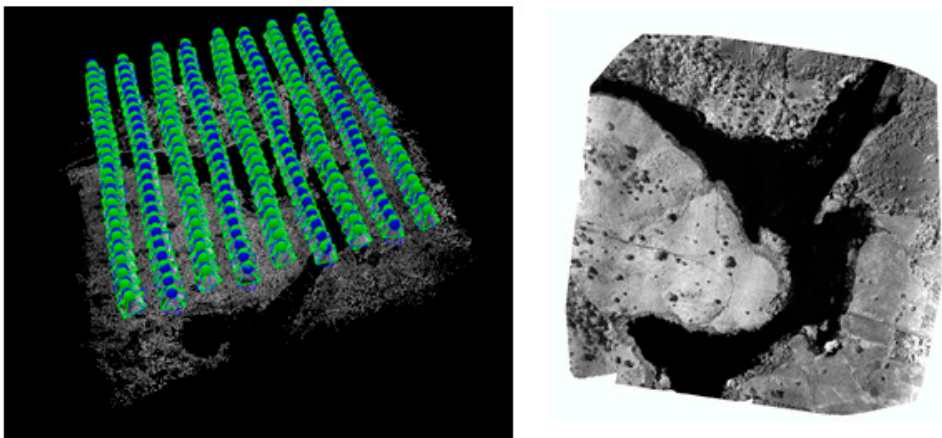

Figure 6. Simplified orthomosaic building process highlighting the position of each image generated through autonomous flights (left) and the steps of image alignment and 3D point cloud in Pix4Dmapper (center) in the Paranoá (a) and Corumbá IV (b) reservoirs. 
Table 2. Summary of the field sampling trips realized for this study.

\begin{tabular}{|c|c|c|c|c|c|c|c|c|c|}
\hline \multirow{2}{*}{ Date in 2018} & \multirow{2}{*}{ Local } & \multirow{2}{*}{$\theta$} & \multirow{2}{*}{ Samples } & \multicolumn{3}{|c|}{ TSS $\left(\mathrm{mg} \mathrm{L}^{-1}\right)$} & \multicolumn{3}{|c|}{$\mathrm{Z}_{\mathrm{SD}}(\mathrm{cm})$} \\
\hline & & & & Min & $\operatorname{Max}$ & Average & Min & Max & Average \\
\hline $03 / 02$ & Corumbá & $46^{\circ}$ & 5 & 23 & 36.2 & 31.2 & 30 & 37 & 36.2 \\
\hline $03 / 29$ & Corumbá & $51^{\circ}$ & 5 & 5 & 15.6 & 12.6 & 41 & 71 & 47.6 \\
\hline $05 / 18$ & Corumbá & $67^{\circ}$ & 5 & 1 & 2.2 & 1.7 & 215 & 270 & 243 \\
\hline $09 / 12$ & Paranoá & $55^{\circ}$ & 7 & 8.8 & 15.6 & 12 & 40 & 100 & 75.5 \\
\hline $10 / 31$ & Paranoá & $49^{\circ}$ & 4 & 4.4 & 186.8 & 50.8 & 5 & 79 & 57 \\
\hline $11 / 02$ & Paranoá & $47^{\circ}$ & 12 & 2.7 & 43.2 & 12.6 & 13 & 127 & 63.4 \\
\hline $11 / 09$ & Paranoá & $56^{\circ}$ & 1 & & 73.2 & & & 18 & \\
\hline $11 / 13$ & Paranoá & $72^{\circ}$ & 1 & & 78.8 & & & 14 & \\
\hline $12 / 05$ & Paranoá & $70^{\circ}$ & 1 & & 68.2 & & & 21 & \\
\hline
\end{tabular}

ө: Solar Zenith Angle at the time of unmanned aerial surveys.

The Sequoia camera provides a communication system via a Wi-Fi network and thus can be configured and programmed to acquire images on any device with an internet browser through an Internet Protocol code. Using this system, the Sequoia was programmed to acquire images every $5 \mathrm{~m}$ through its GPS/IMU system during the flight plan. An average of 1388 and 864 images were generated in Paranoá and Corumbá IV surveys, respectively.

\subsubsection{Multispectral Images Processing}

All multispectral images were processed using Pix4Dmapper software. Orthomosaics containing at-sensor reflectance pixel values were generated using Structure from Motion (SfM) photogrammetric technology. SfM involves automatic identification of similar features in a set of overlap images through a bundle adjustment procedure [22]. This is the mechanism for building orthomosaics in Pix4Dmapper, including the steps of images alignment and creation of a 3D point cloud, triangle mesh, and digital surface model (DSM) (Figure 6).

Considering overlapping images, Pix4Dmapper calculated the reflectance values for each pixel of the orthomosaics using a weighted average of the pixels in all of the original images that correspond to this particular pixel but assigning more weight to images where the pixel is more central. The image pixel value depends on a series of factors that include sensor settings, sensor properties, and scene conditions. Radiometric corrections are applied to improve the quality of the data using the camera, irradiance, and sun angle parameters for clear skies and camera and irradiance for overcast skies. These parameters are obtained from the Exif metadata for each image. The camera parameters are exposure time, shutter speed, vignetting, dark current, and ISO value. The irradiance sensor provides a record of the light conditions during the flight in the same spectral bands as the ones captured by the multispectral sensor. The sun angle parameter takes into account the direction of the incoming sun ray, and its projection onto the scene and onto the sun sensor. Thus, Pix4Dmapper can normalize the images captured during the flight and thus allows comparing images taken in different illumination conditions [23].

\subsection{In Situ Measurements}

Figures 3 and 4 shows the sampling points where we collected field data during unmanned airborne surveys. Spectroradiometric data were collected during two surveys over the Corumbá IV reservoir (March 29th, 2018 and May 18th, 2018). Water quality parameters, namely TSS concentration and water transparency $\left(Z_{S D}\right)$, were measured during all flight campaigns (Table 2).

Spectroradiometric data were recorded using TriOS RAMSES hyperspectral spectroradiometer following the protocol proposed by Mobley [24] for above water measurements. Downwelling irradiance $\left(E_{d}\right)$ was measured using a cosine sensor. Upwelling radiance $\left(L_{u}\right)$ was measured with a $40^{\circ}$ off-nadir viewing angle and a $135^{\circ}$ azimuth angle from the sun during the drone surveys according 
to [25]. For direct comparison with drone-derived at-sensor reflectance, we computed reflectance $(R)$ as $R=L_{u} / E_{d}$.

Water surface samples ( $20 \mathrm{~cm}$ deep) were collected at the sampled points and processed at the Geochemistry Laboratory of the University of Brasília to determine TSS concentrations according to the methodology described in [26]. The water samples were filtered under a low vacuum Millipore membrane filter $\left(0.45 \mu \mathrm{m}\right.$ porosity). Jointly, Secchi disk depth $Z_{S D}$ estimates were made as a measure of water transparency.

\subsection{TSS Bio-Optical Models}

The optical properties of water are the basis for the development of bio-optical models for estimating $\mathrm{OAC}$, such as the suspended inorganic matter and photosynthetic pigments. Bio-optical models are classified in different categories: empirical, semi-empirical, semi-analytical, quasi-analytical, and analytical $[4,27]$.

The semi and quasi-analytical models are applied to estimate the optical properties in the water column. They are based on inversion of radiative transfer theory to establish relationships among the apparent and inherent optical properties, which are computed through several analytical and empirical steps $[27,28]$. In summary, the main difference between these models is in the process of estimating absorption and backscattering $[4,27]$.

Empirical and semi-empirical models are based on statistical relationships between the water components measured in situ and the radiometric data measured by a sensor. The difference is that the empirical models do not rely on the physical theory relating optical properties to water components and, therefore, these algorithms are developed using statistical tests seeking the best arrangement of bands with the concentrations of the water component of interest. Semi-empirical models are developed through physical bases based on the spectral behavior of the water optical properties, mainly light absorption and scattering, concerning the concentrations of the water optically active components [4,27].

There are a wide variety of TSS bio-optical models applied in continental waters with a large range of concentration levels and with multiple radiometric data sources: spaceborne, airborne, and in situ sensors $[3,28,29]$. Some of these models, developed for the main spaceborne sensors used for inland waters (Landsat, Spot, Meris, and Modis), were applied to the Sequoia camera bands with adjustment in the parameters of the statistical models according to the data set obtained in this work. Single band models and simple band ratios were tested based on the Sequoia bands and adjusted to the TSS data collected for this work. All models tested are detailed in Section 3.2 (Table 3).

\section{Results}

\subsection{In situ and Airborne Surveys Data}

Six airborne surveys and simultaneous field sampling campaigns were carried over the Paranoá reservoir and three over the Corumbá $I V$ reservoir. Table 2 presents the field sampling data. TSS and $Z_{S D}$ varied significantly from the rainy to the dry seasons in both reservoirs.

Figure 7 presents the orthomosaics, processed with Pix4Dmapper, of Sequoia camera spectral bands over Paranoá and Corumbá IV reservoirs acquired on October 31st, 2018 and March 2nd, 2018, respectively.

Figure 8 presents the color composite (NIR/Red/Green) for all surveyed dates, highlighting the presence of sediment in the rainy periods at the inlet. The flights made with mean and high solar zenith angle conditions resulted in sun glint absence in practically all orthomosaics, except for the 2018/03/02, 10/31, and 11/02 surveys which had visible glints at the border of the orthomosaics. 


\subsection{Bio-Optical Models Assessment and TSS Mapping}

Figure 9 displays the behavior of at-sensor reflectance as a function of TSS concentration for the four Sequoia spectral bands. We observed that dispersion decreased from the green to the NIR band. At shorter wavelengths, we observed a rapid saturation of the at-sensor reflectance between 40 and $80 \mathrm{mg} \mathrm{L}^{-1}$. At-sensor reflectance-TSS relationship becomes nearly linear in the red-edge band and fully linear in the NIR band over the range of concentrations observed in the study (i.e., $0-180 \mathrm{mg} \mathrm{L}^{-1}$ ). We did not observe any site or time dependency in the NIR and red-edge bands. The NIR single band algorithm presented the best performance (Table 3 and Figure 9) for a large TSS range (1 to $\left.\sim 180 \mathrm{mg} \mathrm{L}^{-1}\right)$. At NIR wavelengths, the reflectance is mostly a function of suspended particle backscattering, and pure water dominates absorption because the interference of the other optical active constituents is absent [30].

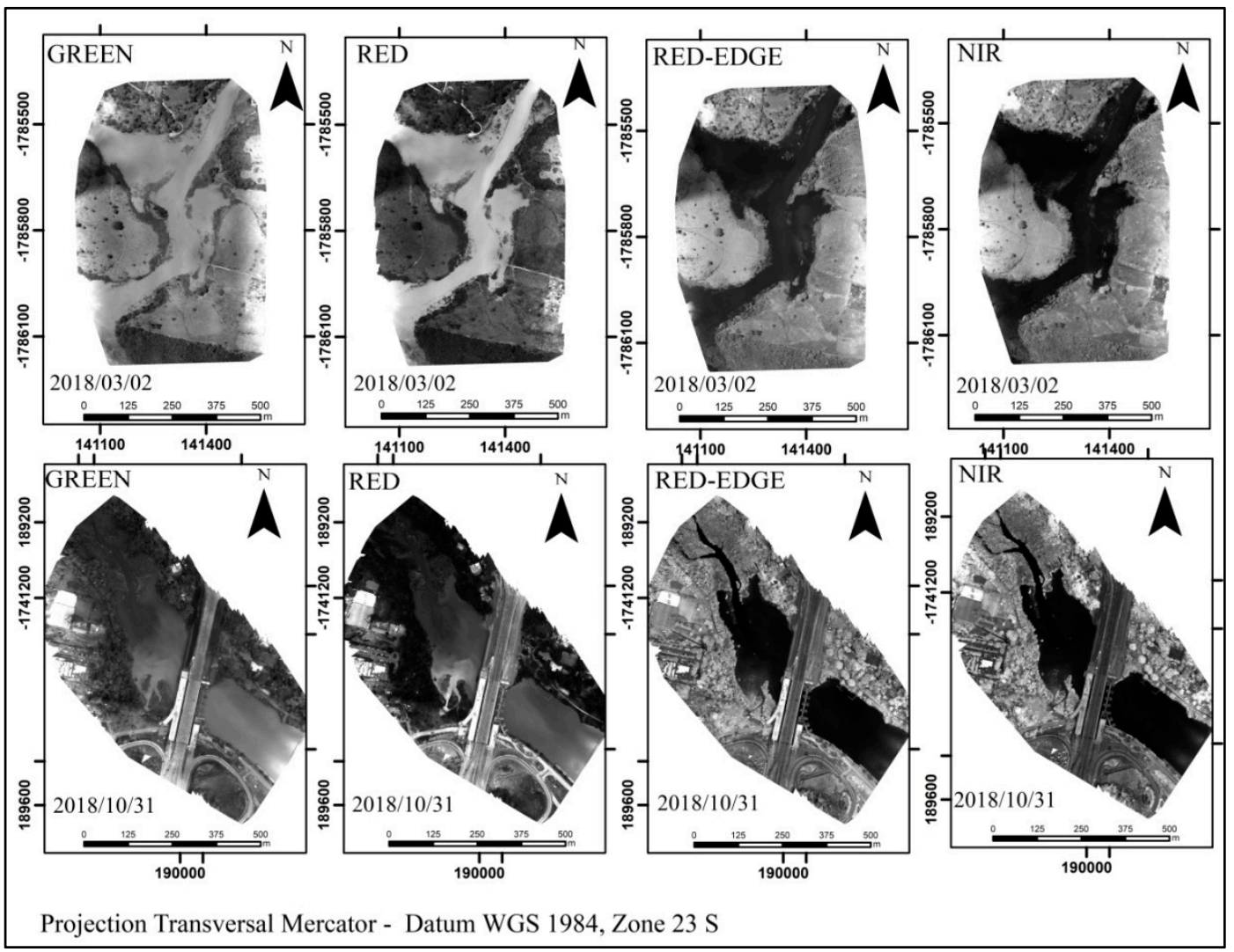

Figure 7. At-sensor reflectance orthomosaics of Sequoia bands in specific high TSS dates in Paranoá and Corumbá.

The bio-optical models for TSS calculation were reproduced from literature or derived from regression analysis between the at-sensor reflectance values of the Parrot Sequoia bands and the TSS in situ data collected simultaneously. Table 3 presents all the tested algorithms and statistical results.

Table 3 shows that strong correlations $\left(R^{2}>0.9\right)$ were obtained for models using the multispectral bands of the Sequoia camera. Single band NIR and red-edge based models performed better (RMSE varying from 7.8 to $10.3 \mathrm{mg} \mathrm{L}^{-1}$, respectively) than models based on red and green bands (RMSE of 19 to $28 \mathrm{mg} \mathrm{L}^{-1}$ ), even for the models adapted from the literature. Other models were used from the literature, obtaining lower performance with an RMSE varying from 22 to $306 \mathrm{mg} \mathrm{L}^{-1}$. One model was used without adjusting its statistical parameters according to the local data series. This model was originally successfully applied to turbid Amazon waters on MODIS images (Table 3-\# 13) but it showed the lowest performance on our test sites, evidencing the need to adjust for the camera spectral bands and test site. 


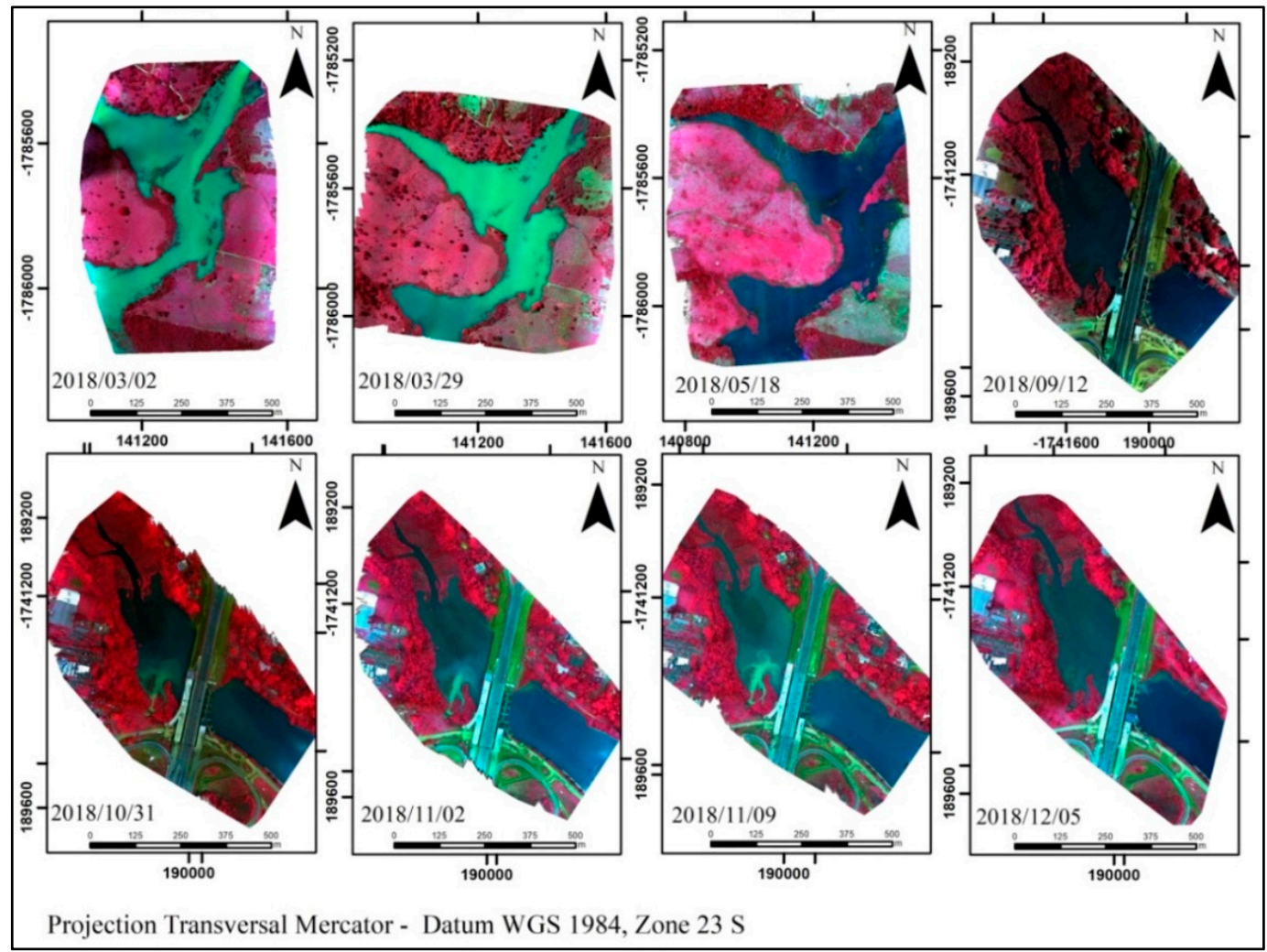

Figure 8. NIR/red/green color composite band for all surveyed dates in Paranoá and Corumbá IV.

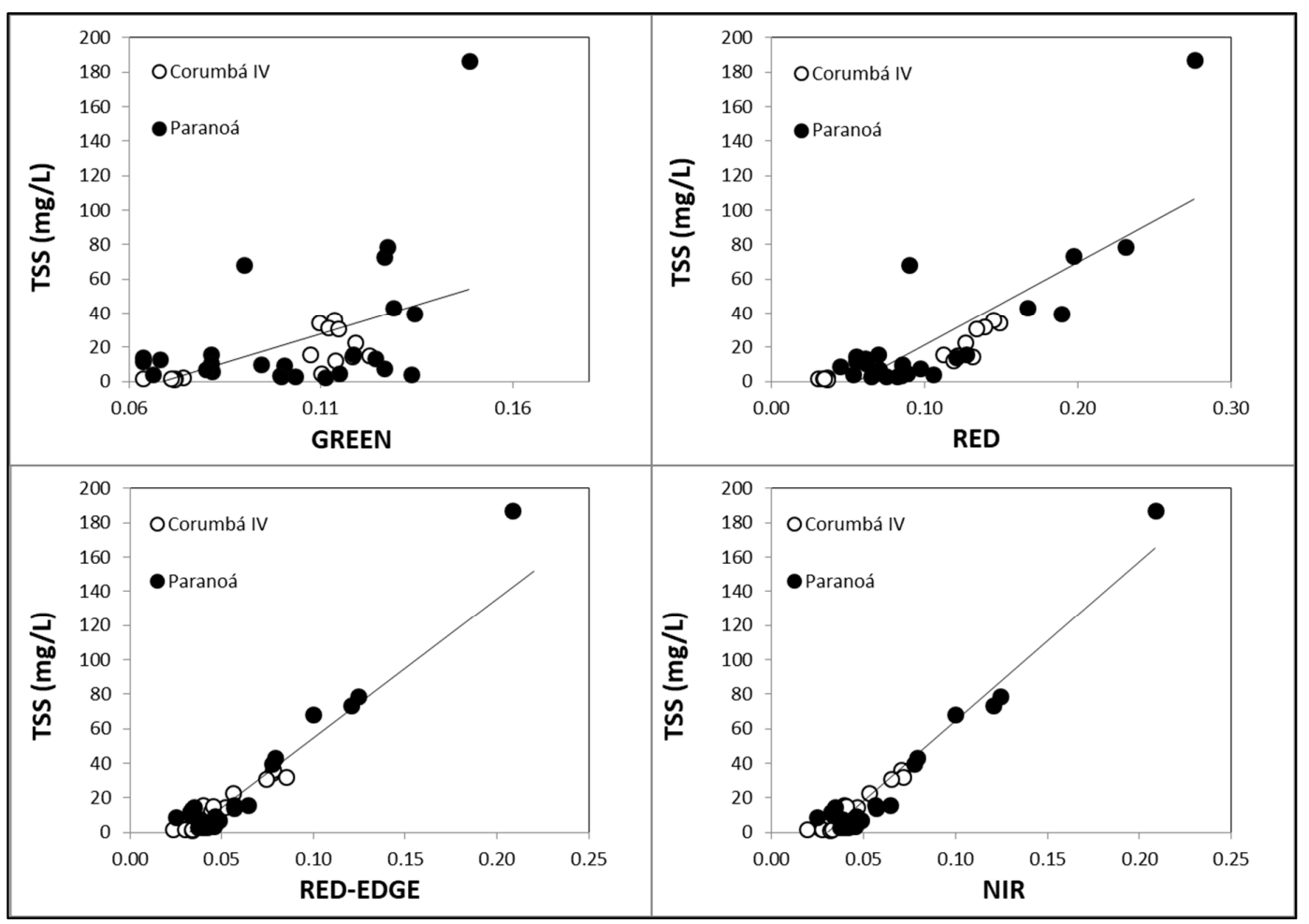

Figure 9. Scatter plots of all Sequoia bands and the total suspended solids (TSS) concentrations in study areas, Corumbá IV and Paranoá. 
Table 3. TSS bio-optical models and statistical results.

\begin{tabular}{ccccc}
\hline Model No. & Reference & Algorithm & $\mathbf{R}^{\mathbf{2}}$ & RMSE $\left(\mathbf{m g ~ L}^{-\mathbf{1}}\right)$ \\
\hline 1 & This study & TSS: $926.7^{*} \mathrm{~N}-28.2$ & 0.94 & 7.8 \\
2 & This study & TSS: $810.3^{*} \mathrm{RE}-26.1$ & 0.90 & 10.3 \\
3 & {$[31]^{* \mathrm{~b}}$} & TSS: $126.3^{*}(\mathrm{~N} / \mathrm{G})-44.3$ & 0.80 & 14.6 \\
4 & This study & TSS: $484.3^{*} \mathrm{R}-27.2$ & 0.66 & 19.0 \\
5 & This study & TSS: $80.7^{*}(\mathrm{R} / \mathrm{G})-55.2$ & 0.65 & 19.2 \\
6 & {$[32]^{* \mathrm{c}}$} & TSS: $280.3^{*}(\mathrm{RE} /(\mathrm{G}+\mathrm{R})-57.7$ & 0.51 & 22.6 \\
7 & {$[33]$} & TSS: $\left(327.8^{*} \mathrm{R} / 1-(\mathrm{R} / 17.1)\right)+1.9$ & 0.66 & 24.7 \\
8 & {$[34]^{* a}$} & TSS:-46.8*(G/R)+76.6 & 0.34 & 26.2 \\
9 & This study & TSS: $675.3^{*} \mathrm{G}-46.2$ & 0.25 & 28.1 \\
10 & {$[33]$} & TSS: $\left(120.8^{*} \mathrm{G} / 1-(\mathrm{G} / 11.2)\right)+3.1$ & 0.25 & 31.7 \\
11 & {$[33]$} & TSS: $(1491.5 *$ & 0.89 & 72.8 \\
12 & {$[33]$} & RE/1-(RE/19.6))+1.1 & & 76.5 \\
13 & {$[35]^{* d}$} & TSS: $(1701.5 *$ & 0.94 & 306.1 \\
\hline
\end{tabular}

* Bio-optical models adapted from orbital images $={ }^{a}$ : Landsat; ${ }^{b}$ : Spot; ${ }^{c}$ : Meris; ${ }^{d}$ : Modis. G: green; R: red; RE: red-edge; N: NIR.

We analyzed the spatial pattern of the drone-derived TSS concentration along a transect beginning at a storm drainage network outlet into the Paranoá reservoir. TSS maps were produced using the models listed in Table 3 and for all the survey dates and compared with field sampling data whenever available. Figure 10 shows the variability of the water color along the transect in the Paranoa reservoir for the 2018/09/12, 2018/10/31, 2018/11/02, and 2018/11/09 surveys, respectively, representing low TSS concentration (i.e., 8 to $10 \mathrm{mg} \mathrm{L}^{-1}$ ), intermediate TSS concentration (i.e., $\sim 6$ to $\sim 44 \mathrm{mg} \mathrm{L}^{-1}$ ), high TSS concentration $\left(74 \mathrm{mg} \mathrm{L}^{-1}\right)$, and very high TSS concentration $\left(187 \mathrm{mg} \mathrm{L}^{-1}\right)$.

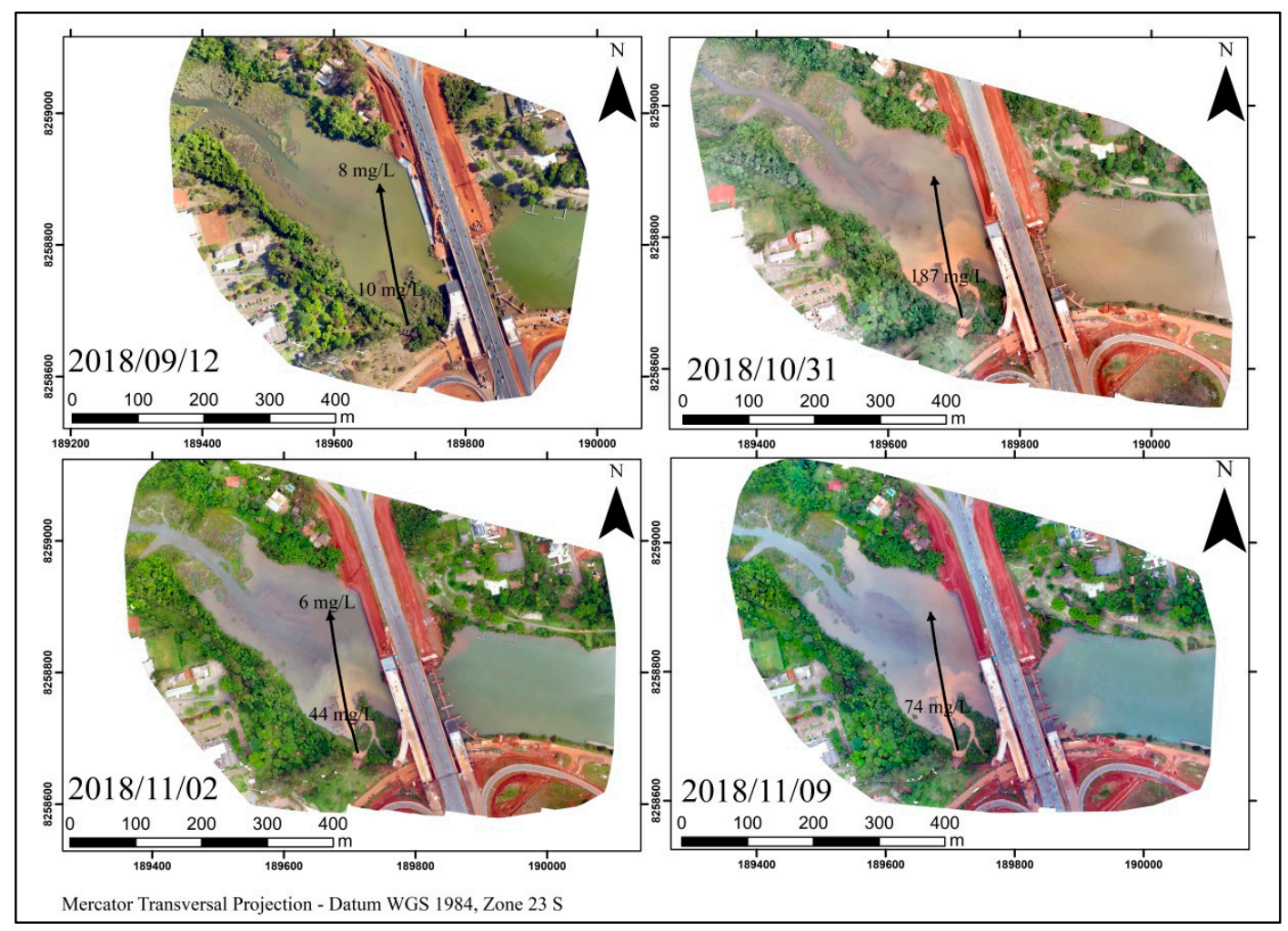

Figure 10. Real color orthomosaics, obtained from the DJI Phantom 4 camera, of the Paranoa reservoir for four dates. The black arrow is the transect line under the TSS sample points collected during the field surveys. 
Figure 11 shows the drone-retrieved TSS concentration calculated with the more consistent models (RMSE < $32 \mathrm{mg} \mathrm{L}^{-1}$ ) (Model \#1-Table 3) as a function of distance along the transect for the October 31st, 2018 survey (Figure 10). It can be seen that the selection of the model is an important step, as the results present a wide range of TSS concentrations.

Figure 11 shows three groups of models concerning the TSS concentration profile extracted from the transect. The first group stands for the most robust models (\#1, \#2, and \#3), for which the retrieved TSS values near the river inlet (pixel 0) is close to the concentration measured that day $\left(187 \mathrm{mg} \mathrm{L}^{-1}\right.$, Figure 10). Those models detected the dramatic TSS concentration decrease from the urban drainage inlet into the reservoir, indicating a strong siltation process that day. The second group of models (\#4, $\# 7$, \#5, and \#6) represents the models that delivered TSS concentration estimates at the drainage inlet of about $100 \mathrm{mg} \mathrm{L}^{-1}$, significantly lower than the effective concentration measured that day, and showed medium TSS concentrations far into the reservoir. The third group of models (\#9 and \#8) provided TSS concentrations of about $50 \mathrm{mg} \mathrm{L}^{-1}$ at the drainage inlet and showed very distinct behavior in relation to the others, with no clear TSS concentration decrease until far into the lake, failing to properly detect the extension of the suspended sediment plume, with TSS concentration remaining almost constant for almost the entire transect.

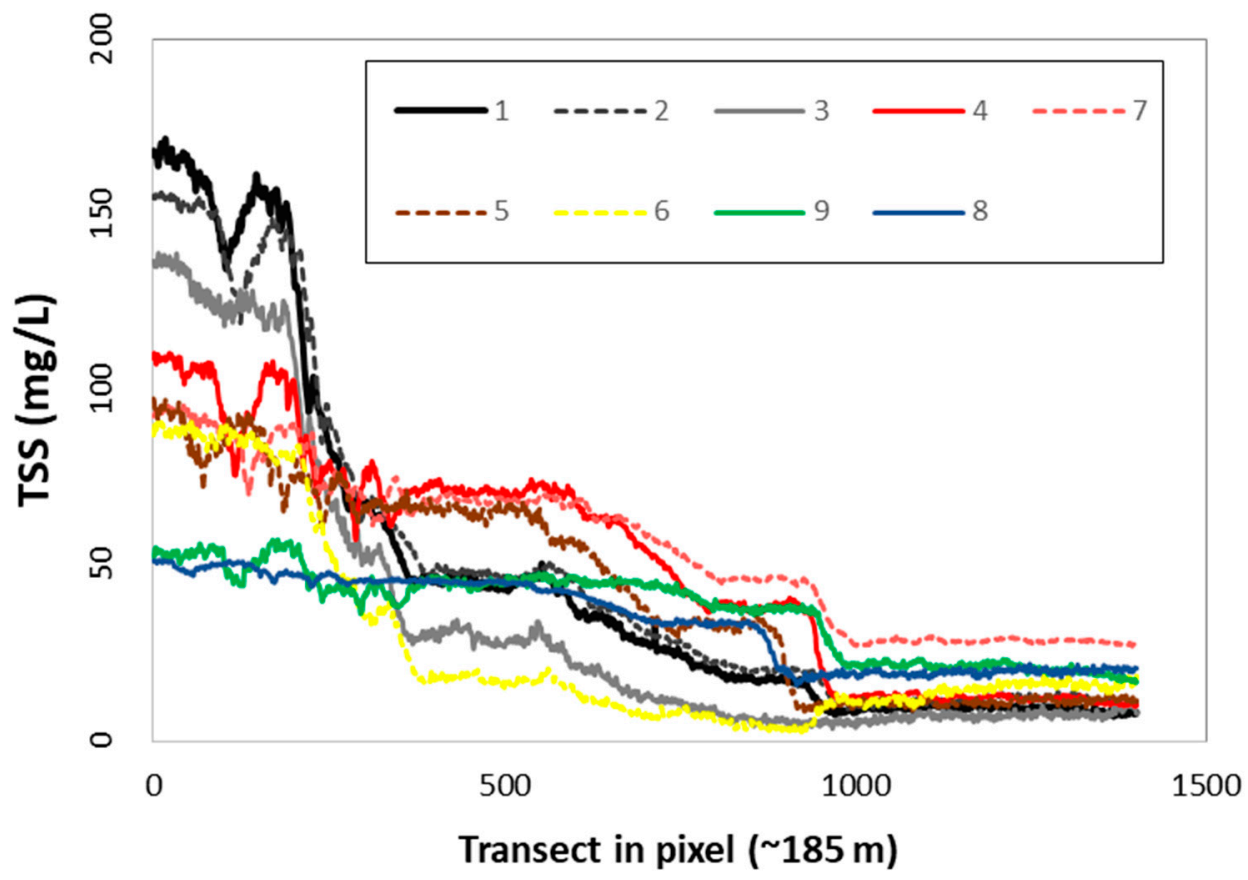

Figure 11. Estimated TSS values using different retrieval models along an arbitrary transect on 2018/10/31 in the Paranoá reservoir. Model are identified by their number (see Table 3).

We selected the best retrieval model (lower RMSE) selected from Table 3, which is based solely on the NIR band (model \#1), to map the variability of the TSS at the reservoir's surface for all the surveys. Figure 12 shows the temporal TSS mapping in the inlet areas of the Paranoá and Corumbá IV reservoirs.

We analyzed the TSS maps along the same transect in the Paranoá reservoir used for Figure 10 and compare the TSS mapping accuracy concerning the field samples acquired during each survey (Figure 13). For the surveys realized during rainy days (October 31st, November 2nd and 9th, and December 5th), the drone-retrieved TSS concentrations were close to the field measurements: only 3 points had a difference of greater than $15 \mathrm{mg} \mathrm{L}^{-1}$ : one on October 31st and two on November 9th. Despite these fluctuations, the estimated TSS data had an RMSE of $7.8 \mathrm{mg} \mathrm{L}^{-1}$ (Table 3) and were thus coherent with the seasonality of the rain distribution. The concentrations during the 2018/09/12 survey are the lowest recorded during the study, as it occurred during the dry season with almost no inflow into the reservoir. During the rainy period, there is a high TSS load flowing from the urban 
drainage inlet, especially in 2018/10/31. For that data, the drone-retrieved TSS concentration described consistently the gradual decrease of the sediment load, especially during the rainy period due to the variations of the rainfall regime.

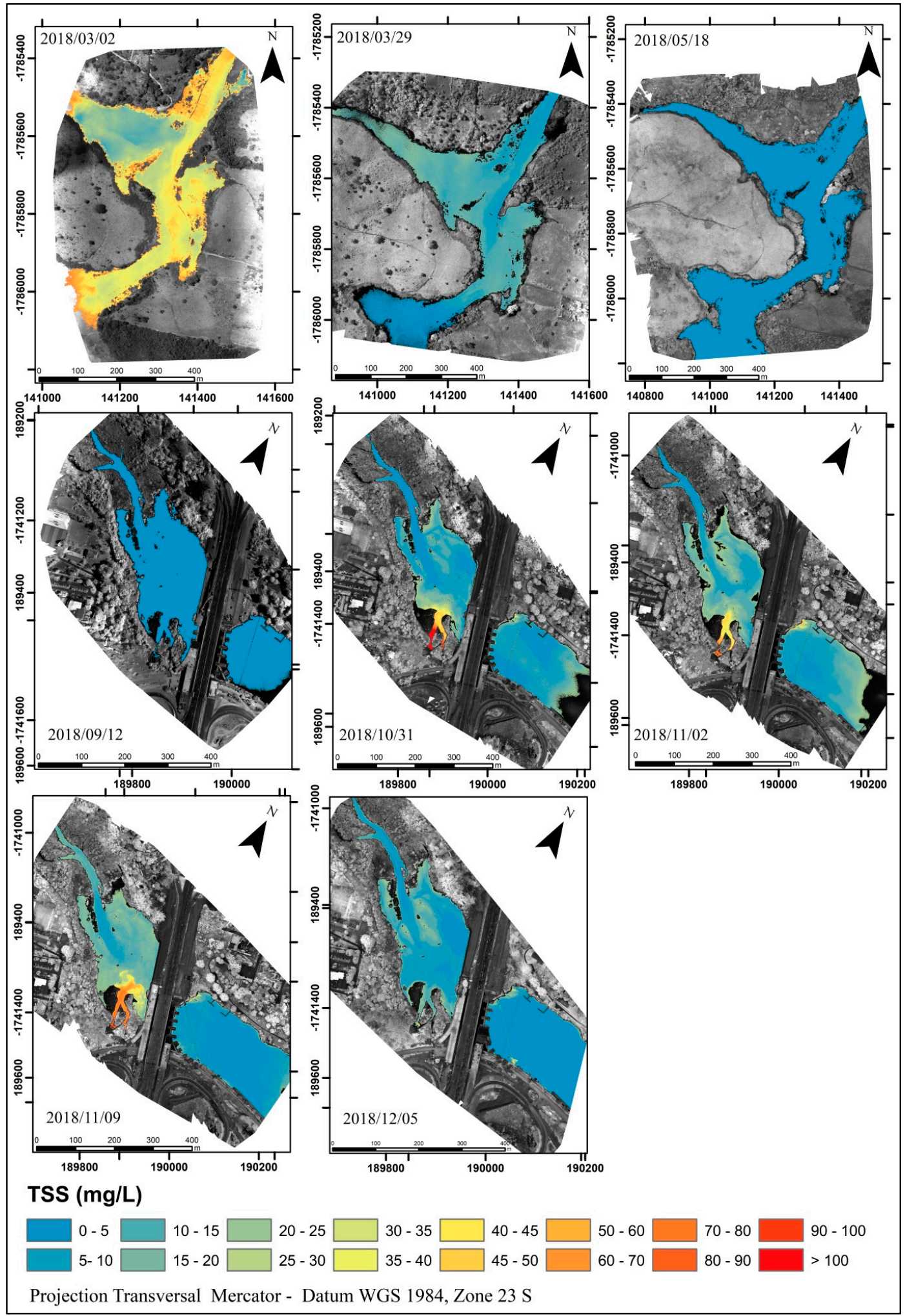

Figure 12. Time series of TSS concentration maps in the study areas, using model \#1 (single NIR band). 


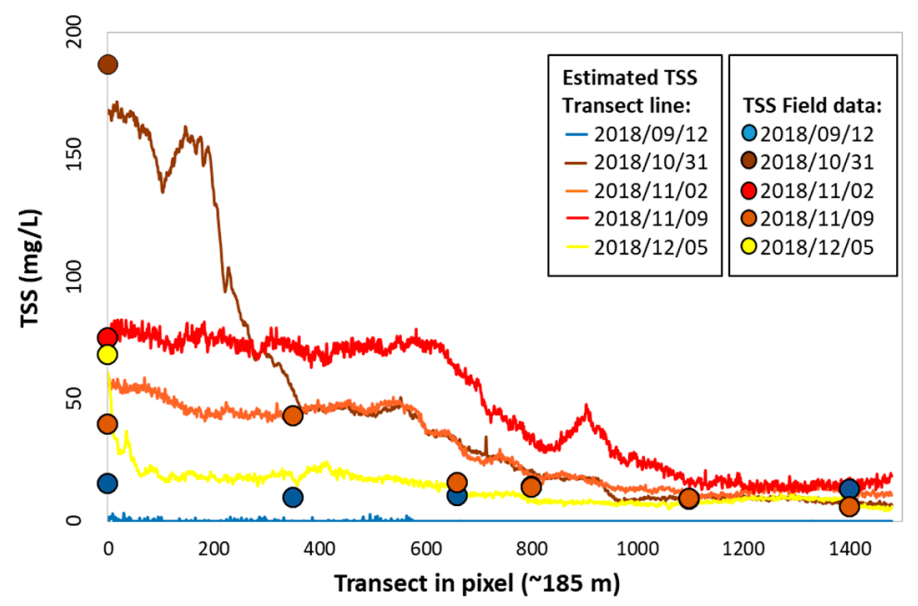

Figure 13. Measured and estimated TSS concentrations, using the Sequoia camera NIR band (model \#1), extracted along the transect exhibited in Figure 10 for all survey dates in the Paranoá reservoir.

\section{Discussion}

Spaceborne mapping of inland water quality is very difficult during the rainy season, especially in the tropics, due to the persistent cloud coverage that dramatically limits the number of cloud-free acquisitions. This problem becomes even more complicated when very small areas are considered. Figure 14 shows true color RGB composite Sentinel 2 MSI orbital images totally or partially covered by clouds acquired simultaneously to some drone surveys: 2018/03/02 over Corumbá IV reservoir and 2018/10/31 and 11/02 over Paranoá reservoir. This comparison illustrates the advantage of a drone in relation to spaceborne sensors for water quality monitoring of the reservoir. The use of drones makes it possible to increase the acquisition frequency, representing a major benefit when dealing with siltation processes that usually occur during strong rainfall events associated with persistent cloud coverage preventing the use of satellite images.

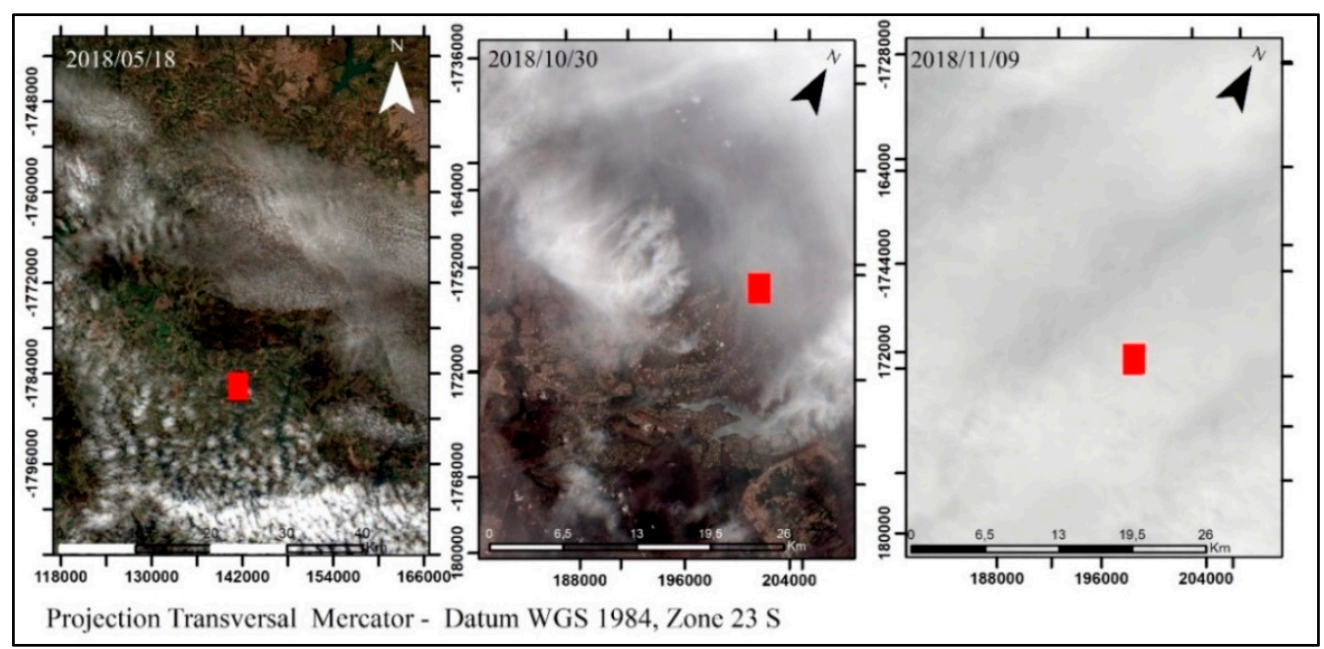

Figure 14. True color red/green/blue (RGB) composite band of Sentinel 2 images totally or partially covered by clouds in dates of airborne surveys.

\subsection{Radiometric Accuracy}

Our results showed that TSS retrieval accuracy was better when using the NIR channel than when using shorter wavelengths. The NIR single band model proved to be the channel best correlated with field samples of TSS concentration. The single NIR channel was applied for consistent TSS mapping over the whole period in experimental inlet areas of the Paranoá and Corumbá IV reservoirs. 
It is well-known that reflectance saturates for higher TSS concentration levels at NIR wavelength than in visible wavelengths. As an example, [36] measured in situ remote sensing reflectance at 279 stations in the Amazon basin for a large TSS range (5-620 mg L ${ }^{-1}$ ). Those authors found that NIR wavelengths were suitable for monitoring a large range of TSS concentration and that for the highest concentrations (i.e., greater than $100 \mathrm{mg} \mathrm{L}^{-1}$ ) a band ratio between NIR and red channel performed better. Several other studies obtained good relationships between NIR spectral data and TSS with different remote sensing platforms. [37] observed that in situ spectrum wavelengths between 700 and $800 \mathrm{~nm}$ were the best correlated with TSS concentrations from 30 to $320 \mathrm{mg} \mathrm{L}^{-1}$ on six northern Mississippi reservoirs. [38] reported an $R^{2}$ of 0.7 between the in situ reflectance at $810 \mathrm{~nm}$ and TSS concentration for a $0-64 \mathrm{mg} \mathrm{L}^{-1}$ range in boreal water lakes in Europe. Manned hyperspectral airborne surveys also obtained best relationships by applying NIR wavelengths (705-715 nm) for TSS modeling in clear waters (<36 $\left.\mathrm{mg} \mathrm{L}^{-1}\right)$ in the Mississippi River and its tributaries [7] and Finland lakes [39]. It appears that the use of visible spectral bands may be more appropriate to map water bodies with low TSS concentration (i.e., $0-30 \mathrm{mg} \mathrm{L}^{-1}$ ), as the reflectance would not be subject to saturation and that radiometric accuracy would be better. For water bodies presenting high TSS concentration levels, it is recommended to consider the use of NIR channel and/or band ratios based on empirical or semi-empirical bio-optical models for TSS estimation [2,3,28,29,40]. Although the NIR channel usually shows a strong correlation with TSS concentration when working with field or airborne surveys, NIR band accuracy from spaceborne sensors might be subject to artifacts due to the low reflectance of water bodies that makes the NIR channel highly susceptible to adjacency effects and atmospheric correction residuals [41]. Recent studies evaluated different atmospheric correction methods for Sentinel 2 images and showed that the NIR band obtained poor performance in turbid and dark water in the Amazon [42] and over the Paranoá reservoir [43].

We assessed the Sequoia camera radiometric accuracy using field spectroradiometric data collected during two flights over the Corumbá IV reservoir. The spectroradiometric data were acquired using TriOS Hyperspectral RAMSES radiometers and were convolved with the spectral response function of each channel of the Sequoia camera. Over 12 sampling points, the Sequoia at-sensor reflectance matched the field measurements well, with accuracy decreasing as a function of wavelength. The coefficient of determination varied from $0.98,0.94$, down to 0.42 , and 0.43 for green, red, red-edge, and NIR channels, respectively. Relative RMSE between ground reflectance and at-sensor reflectance was $21.9 \%$, $17.3 \%, 53.2 \%$, and $53.7 \%$ for green, red, red-edge, and NIR channels, respectively. The decrease in the radiometric accuracy towards longer wavelengths can be interpreted as a function of decreasing radiance level over water targets that exhibit much lower radiance in the NIR spectrum than in the visible spectrum, resulting in lower sensor efficiency beyond $700 \mathrm{~nm}$. Consequently, a trade-off exists between radiometric accuracy and the spectral band ability to retrieve TSS concentration. Consequently, the user may need to define which channel to use as a function of water optical properties.

Although the single NIR band model obtained consistent validation overall, making it possible to detect the inflow of high TSS concentrations into the reservoirs during the rainy season, this model has limitations for mapping low concentrations. This can be seen in Figures 12 and 13 . For the 2018/09/12 survey, the estimated TSS concentrations were all lower than $5 \mathrm{mg} \mathrm{L}^{-1}$, while the observed values had an average concentration of $12 \mathrm{mg} \mathrm{L}^{-1}$ (Table 2). We further analyzed the low TSS concentration conditions.

TSS bio-optical models with RMSE $<32 \mathrm{mg} \mathrm{L}^{-1}$ in Table 3 were tested exclusively for 2018/09/12 (Table 4). Such results demonstrate that the NIR single band model obtained higher RMSE value. Other models obtained better performance (RMSE $<10 \mathrm{mg} \mathrm{L}^{-1}$ ), mainly using green and red bands. Thus, models using red and green bands (Table 3) were tested to estimate low TSS conditions (Table 4). Figure 15 presents a comparison of three models for the 2018/09/12 survey. It can be seen that the tested models were able to deliver TSS concentrations that were not underestimated, in contrast to the NIR single band (Figure 12). 
Table 4. TSS bio-optical models and statistical results for the 2018/09/12 survey.

\begin{tabular}{|c|c|c|c|c|}
\hline Model No. & Reference & Algorithm & $\mathbf{R}^{2}$ & RMSE $\left(\mathrm{mg} \mathrm{L}^{-1}\right)$ \\
\hline 1 & This study & TSS: $926.7 * \mathrm{~N}-28.2$ & 0.10 & 14.3 \\
\hline 2 & This study & TSS: $810.3 *$ RE-26.1 & 0.48 & 11.7 \\
\hline 3 & {$[31] * b$} & TSS:126.3* $(\mathrm{N} / \mathrm{G})-44.3$ & 0.82 & 8.1 \\
\hline 4 & This study & TSS: $484.3 *$ R-27.2 & 0.10 & 11.7 \\
\hline 5 & This study & TSS: $80.7 *(R / G)-55.2$ & 0.22 & 4.1 \\
\hline 6 & {$[32] * c$} & TSS: $280.3 *(\mathrm{RE} /(\mathrm{G}+\mathrm{R})-57.7$ & 0.80 & 9.5 \\
\hline 7 & {$[33]$} & TSS: $(327.8 * \mathrm{R} / 1-(\mathrm{R} / 17.1))+1.9$ & 0.10 & 11.1 \\
\hline 8 & {$[34]^{* a}$} & TSS:-46.8* $(\mathrm{G} / \mathrm{R})+76.6$ & 0.25 & 9.5 \\
\hline 9 & This study & TSS: $675.3 * \mathrm{G}-46.2$ & 0.10 & 13.1 \\
\hline 10 & [33] & TSS: $(120.8 * \mathrm{G} / 1-(\mathrm{G} / 11.2))+3.1$ & 0.10 & 2.8 \\
\hline
\end{tabular}

* Bio-optical models adapted from orbital images $={ }^{\mathrm{a}}$ : Landsat; ${ }^{\mathrm{b}}:$ Spot; ${ }^{\mathrm{c}}$ : Meris; ${ }^{\mathrm{d}}$ : Modis.
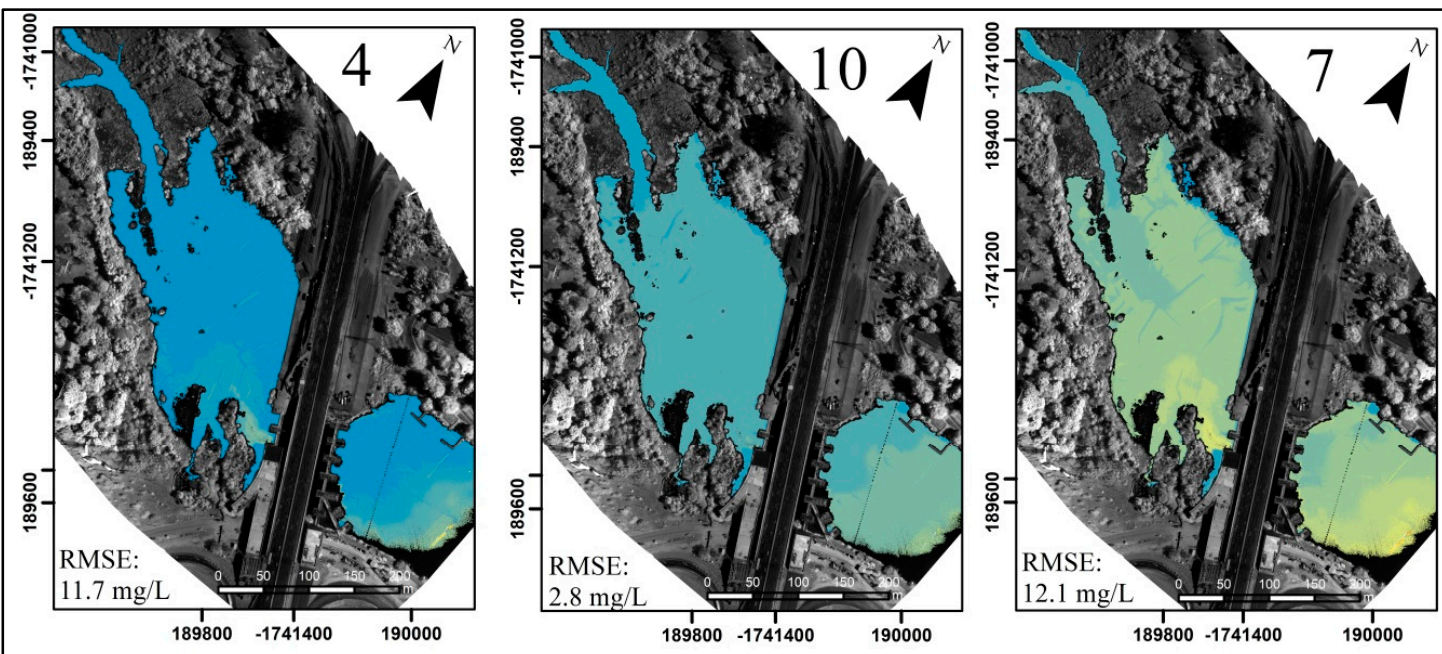

TSS (mg/L)

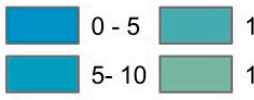

$10-15$
$15-20$
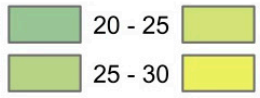

$30-35$
$35-40$

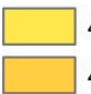

$40-45$
$45-50$

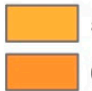

$50-60$

$60-70$

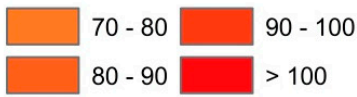

Projection Transversal Mercator - Datum WGS 1984, Zone 23 S

Figure 15. 2018/09/12 TSS maps in the Paranoá from models using green and red bands (models are labeled following Table 4).

Figure 16 presents the TSS concentrations along the transect (Figure 10) for the same models as presented in Figure 15 (models \#4,\#10, and \#7), and the NIR model. This analysis confirms that model \#4 and model \#10 (i.e., based on red and green bands, respectively) were more successful in estimating robustly low TSS concentrations. Model \#10 displayed a rather constant TSS concentration estimate with no trend along the transect. Model \#4 showed greater oscillations in the distribution of TSS along the transect and seemed to better reproduce the TSS spatial pattern. Model \#1 and \#7 were less suitable, as the NIR model strongly underestimated the measured TSS concentration while model \#7 produced systematically overestimated TSS concentration values. 


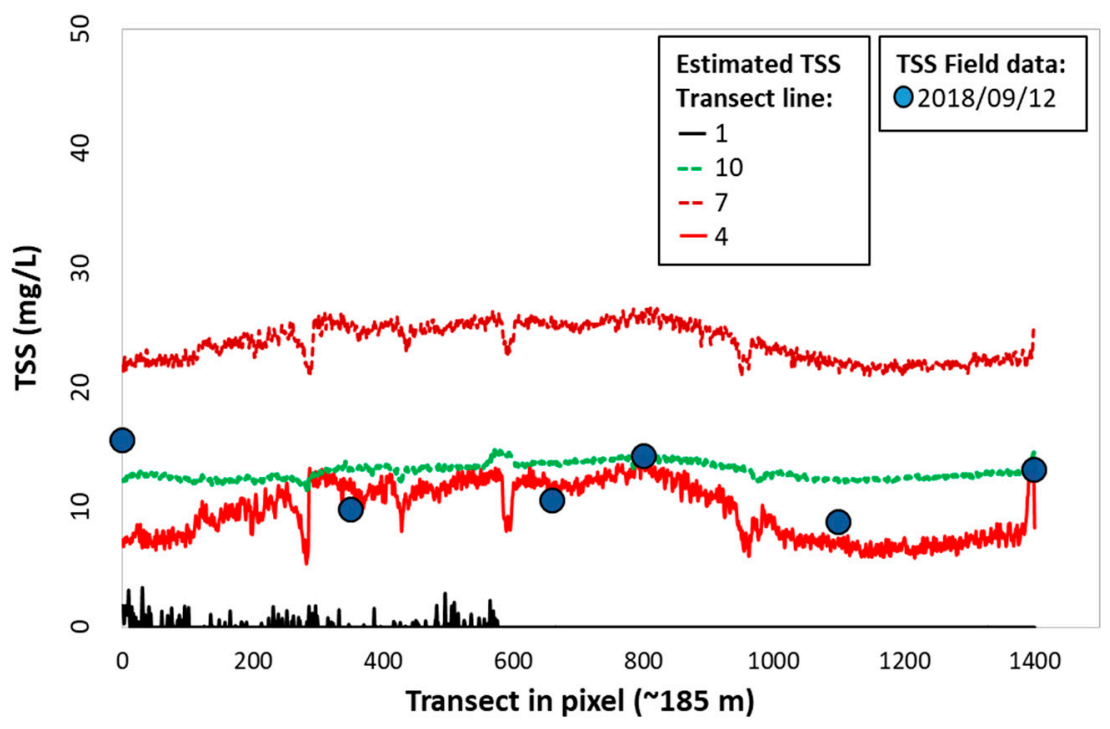

Figure 16. Field and estimated total suspended solids (TSS) concentrations for the 2018/09/12 survey in the Paranoa reservoir, for different models using the near-infrared (NIR), green and red bands of the Sequoia camera, extracted along the transect exhibited in Figure 10 (models are labeled following Table 4).

\subsection{Reservoir Siltation Mapping}

Siltation in the Paranoá reservoir is a major concern, as nearly $6 \%$ of its surface has disappeared since 1960 , representing a mean annual loss of $0.05 \mathrm{~km}^{3}$. The sedimentation rates are highly variable, changing from $0.2 \mathrm{~cm} /$ year $^{-1}$ in the central part of the reservoir to $7 \mathrm{~cm} /$ year at some inlets. Another important point is that the reduction in storage capacity prevents the reservoir from providing the services for which it was designed, because the water level operation range of Lake Paranoá is very narrow, only $1 \mathrm{~m}$. For this reason, it is very important to know the sediment inflow, the sediment plume location, and the sedimentation rate that can affect the storage capacity of the reservoir. However, it is extremely difficult to calculate the silting of this region using conventional bathymetry surveys as most of the siltation areas occur in very shallow depths (less than $2 \mathrm{~m}$ ) [44-46].

In addition, as the Paranoá is an urban reservoir, the storm drainage network presents numerous inlets into the reservoir, which are sources of sediment that are not monitored by conventional monitoring. These inlets discharge a large amount of sediment that depends on the local rainfall regime and the stage of urbanization of the area covered by the drainage system. In this context, with a shallow region of complex shape and with a lot of small drainage inlets, the use of drones makes it possible to identify the sources of sediment inflow and the extent and propagation of the sediment plume, even during heavy rain events associated with persistent cloud cover that prevents the use of satellite images.

The TSS distribution maps in the inlet areas show the advantages of drone-borne remote sensing imagery: operational flexibility and fine spatial and temporal resolution. The Sequoia camera was able to identify TSS gradients from 0 to $\sim 50 \mathrm{mg} \mathrm{L}^{-1}$ in Corumbá IV and from 0 to $>100 \mathrm{mg} \mathrm{L}^{-1}$ in Paranoá, highlighting the high concentrations from the urban drainage flow near sampling point 1 (Figure 2) at a level of detail that is restricted to very high spatial resolution images. The beginning of the rainy season in Brasília (city near the Paranoá reservoir) is marked by heavy rains, which promote runoff that transports sediment from urban areas to Paranoá, as observed on 2018/10/31 when there was the highest TSS load in the area. Such results demonstrate the viability of this platform to densify TSS monitoring at the inlet areas of reservoirs. It is a tool that allows identification and quantification of the sources of sediment inputs, helping to understand and to mitigate the siltation process in reservoirs. 


\section{Conclusions}

The low cost and the operational flexibility of unmanned airborne remote sensing platforms allow water quality monitoring at high spatial and temporal resolutions and is especially well suited for small areas where it is difficult to rely on manned airborne and orbital platforms due to technical or financial reasons.

Our study showed that multispectral cameras onboard UAVs, combined with the application of bio-optical models, are robust and practical tools to monitor the spatial distribution of TSS concentration in water bodies. We presented the different steps involved in the mapping from flight planning, at-sensor reflectance orthomosaic generation, TSS retrieval model selection, and final mapping. We showed that the selection of an appropriate radiometric model is essential, as it can result in very different outputs in terms of the TSS concentration level and spatial distribution. A NIR single band model was found to be the most efficient for TSS monitoring during medium to high TSS concentration levels. Bio-optical models using bands at shorter wavelengths (red and green) appeared to be the most appropriate to detect low TSS concentrations during the dry season. It is expected that the methods presented here may be reproduced easily over different regions in the world. The TSS mapping performance was very encouraging, reaching an RMSE of $7.8 \mathrm{mg} \mathrm{L}^{-1}$ for the whole concentration range, and an RMSE of 2.8 $\mathrm{mg} \mathrm{L}^{-1}$ for the clearest water conditions, yielding an accuracy close to conventional water sampling methods but with improved coverage and lower costs.

Robust temporal TSS mapping is a suitable indicator of the siltation process in reservoirs. Although the low-cost unmanned airborne platforms can not monitor large reservoirs entirely, their ultra-high temporal and spatial resolution capacity make them a well-suited platform to identify the sources of sediment production at the inlet areas of reservoirs, as in the case of urban drainage, as well as suspended sediment dispersion within the water body.

Author Contributions: D.O. conceptualized the work (methodology, data acquisition, analysis, and validation) and wrote the original draft manuscript. H.R. participated in the project administration, funding acquisition, supervision, writing, and review. J.-M.M. participated in the planning of the work and the article manuscript, field campaigns, data analysis, validation, data curation, writing, review, and editing. H.B. participated in the field data acquisition, data analysis, and visualization. A.F. participated in the construction of the airborne multispectral platform, flight planning, and image processing. R.C. participated in the construction of the airborne multispectral platform and flight execution. L.S. participated in the field data acquisition, validation data, and visualization. E.M. participated in the flight execution and field data collection. All authors have read and agreed to the published version of the manuscript.

Funding: This research was funded by Financiadora de Estudos e Projetos (FINEP) grant number 01.14.0114.00, by the Fundação de Amparo a Pesquisa do Distrito Federal (FAPDF) grant numbers 23547.93.27555.30052018 and 17457.78.36995.26042017, and by the Coordenação de Aperfeiçoamento de Pessoal de Nível Superior-Brasil (CAPES)Finance Code 001.

Acknowledgments: We acknowledge the partner institutions that integrate the AQUASENSE research group (http://aquasense.igd.unb.br/). The AQUASENSE group is formed by management and research institutions from Brazil and France that contemplate a water quality monitoring network using multiscale Remote Sensing techniques.

Conflicts of Interest: The authors declare not conflict of interest.

\section{References}

1. Palmer, S.; Kutser, T.; Hunter, P.D. Remote sensing of inland waters: Challenges, progress and future directions. Remote Sens. Environ. 2015, 157, 1-8. [CrossRef]

2. Dörnhöfer, K.; Oppelt, N. Remote sensing for lake research and monitoring-Recent advances. Ecol. Indic. 2016, 64, 105-122. [CrossRef]

3. Gholizadeh, M.H.; Melesse, A.; Reddi, L.N. A comprehensive review on water quality parameters estimation using remote sensing techniques. Sensors 2016, 16, 1298. [CrossRef] [PubMed]

4. Ogashawara, I.; Mishra, D.; Gitelson, A.A. Remote sensing of inland waters. In Bio-Optical Modeling and Remote Sensing of Inland Waters; Elsevier B.V.: Amsterdam, the Netherlands, 2017; pp. 1-24. 
5. Olmanson, L.G.; Brezonik, P.L.; Bauer, M.E. Remote sensing for regional lake water quality assessment: Capabilities and limitations of current and upcoming satellite systems. In Advances in Watershed Science and Assessment; Springer: New York, NY, USA, 2015.

6. Moses, W.J.; Sterckx, S.; Montes, M.J.; De Keukelaere, L.; Knaeps, E. Atmospheric correction for inland waters. In Bio-Optical Modeling and Remote Sensing of Inland Waters; Elsevier B.V.: Amsterdam, the Netherlands, 2017; pp. 69-100.

7. Olmanson, L.G.; Brezonik, P.L.; Bauer, M.E. Airborne hyperspectral remote sensing to assess spatial distribution of water quality characteristics in large rivers: The Mississippi River and its tributaries in Minnesota. Remote Sens. Environ. 2013, 130, 254-265. [CrossRef]

8. Markelin, L.; Simis, S.; Hunter, P.; Spyrakos, E.; Tyler, A.; Clewley, D.; Groom, S. Atmospheric correction performance of hyperspectral airborne imagery over a small eutrophic lake under changing cloud cover. Remote Sens. 2016, 9, 2. [CrossRef]

9. Pyo, J.; Ligaray, M.V.; Kwon, Y.; Ahn, M.-H.; Kim, K.; Lee, H.; Kang, T.; Cho, S.B.; Park, Y.; Cho, K.H. High-spatial resolution monitoring of phycocyanin and chlorophyll-a using airborne hyperspectral imagery. Remote Sens. 2018, 10, 1180. [CrossRef]

10. Aasen, H.; Honkavaara, E.; Lucieer, A.; Zarco-Tejada, P.J. Quantitative remote sensing at ultra-high resolution with UAV spectroscopy: A review of sensor technology, measurement procedures, and data correction workflows. Remote Sens. 2018, 10, 1091. [CrossRef]

11. Kislik, C.; Dronova, I.; Kelly, M. UAVs in support of algal bloom research: A review of current applications and future opportunities. Drones 2018, 2, 35. [CrossRef]

12. Yang, G.; Liu, J.; Zhao, C.; Li, Z.; Huang, Y.; Yu, H.; Xu, B.; Yang, X.; Zhu, D.; Zhang, X.; et al. Unmanned aerial vehicle remote sensing for field-based crop phenotyping: Current status and perspectives. Front. Plant Sci. 2017, 8. [CrossRef]

13. Kageyama, Y.; Takahashi, J.; Nishida, M.; Kobori, B.; Nagamoto, D. Analysis of water quality in Miharu dam reservoir, Japan, using UAV data. IEEJ Trans. Electr. Electron. Eng. 2016, 11, S183-S185. [CrossRef]

14. Su, T.-C.; Chou, H.-T. Application of multispectral sensors carried on unmanned aerial vehicle (UAV) to trophic state mapping of small reservoirs: A case study of tain-pu reservoir in Kinmen, Taiwan. Remote Sens. 2015, 7, 10078-10097. [CrossRef]

15. Su, T.-C. A study of a matching pixel by pixel (MPP) algorithm to establish an empirical model of water quality mapping, as based on unmanned aerial vehicle (UAV) images. Int. J. Appl. Earth Obs. Geoinf. 2017, 58, 213-224. [CrossRef]

16. Wei, L.; Zhang, Y.; Zhong, Y.; Wang, Z.; Hu, X.; Lin, L. Inland waters suspended solids concentration retrieval based on PSO-LSSVM for UAV-borne hyperspectral remote sensing imagery. Remote Sens. 2019, 11, 1455. [CrossRef]

17. Menezes, P.H.B.J.; Roig, H.L.; Almeida, T.; Neto, G.B.S.; Isaias, B. Análise da evolução do padrão de uso e ocupação do solo na bacia de contribuição do lago paranoá-Df evolution analysis og the land use pattern in lago paranoá 's watershed-Df. Estud. Geogr. Rev. Eletrôn. Geogr. 2010, 8, 87-105. (In Portuguese)

18. Almeida, W.S.; Souza, N.M.; Reis Junior, D.S.; Carvalho, J.C. Fluvial morphometric analysis of the contributors watersheds around the reservoir of the hydroeletric power plant (HPP) CORUMBÁ IV as indicators of the erosion and sedimente accumulation process. Rev. Bras. Geomorfol. 2013, 2, 135-149.

19. Guan, S.; Fukami, K.; Matsunaka, H.; Okami, M.; Tanaka, R.; Nakano, H.; Sakai, T.; Nakano, K.; Ohdan, H.; Takahashi, K. Assessing correlation of high-resolution NDVI with fertilizer application level and yield of rice and wheat crops using small UAVs. Remote Sens. 2019, 11, 112. [CrossRef]

20. Padró, J.-C.; Carabassa, V.; Balagué, J.; Brotons, L.; Alcañiz, J.M.; Pons, X. Monitoring opencast mine restorations using Unmanned Aerial System (UAS) imagery. Sci. Total Environ. 2019, 657, 1602-1614. [CrossRef]

21. Overstreet, B.; Legleiter, C.J. Removing sun glint from optical remote sensing images of shallow rivers. Earth Surf. Process. Landf. 2016, 42, 318-333. [CrossRef]

22. Westoby, M.J.; Brasington, J.; Glasser, N.F.; Hambrey, M.J.; Reynolds, J.M. 'Structure-from-Motion' photogrammetry: A low-cost, effective tool forgeoscience applications. Geomorphology 2012, 179, 14. [CrossRef]

23. Radiometric-Corrections. Available online: https://support.pix4d.com/hc/en-us/articles/202559509Radiometric-corrections (accessed on 2 September 2019). 
24. Mobley, C.D.; Werdell, J.; Franz, B.; Ahmad, Z.; Bailey, S. Atmospheric Correction for Satellite Ocean Color Radiometry a Tutorial and Documentation of the Algorithms Used by the NASA Ocean Biology Processing Group; NASA Goddard Space Flight Center: Bellevue, WA, USA, 2016.

25. Espinoza Villar, R.; Martinez, J.M.; Le Texier, M.; Guyot, J.L.; Fraizy, P.; Meneses, P.R.; de Oliveira, E. A study of sediment transport in the Madeira River, Brazil, using MODIS remote-sensing images. J. South Am. Earth Sci. 2013, 44, 45-54. [CrossRef]

26. APHA-Association American Public Health. Standard Methods for the Examination of Water and Wastewater; Association American Public Health: New York, NY, USA, 2017.

27. Ogashawara, I. Terminology and classification of bio-optical algorithms. Remote Sens. Lett. 2015, 6, 613-617. [CrossRef]

28. Matthews, M. A current review of empirical procedures of remote sensing in inland and near-coastal transitional waters. Int. J. Remote Sens. 2011, 32, 6855-6899. [CrossRef]

29. Odermatt, D.; Gitelson, A.; Brando, V.; Schaepman, M.E. Review of constituent retrieval in optically deep and complex waters from satellite imagery. Remote Sens. Environ. 2012, 118, 116-126. [CrossRef]

30. Ruddick, K.G.; De Cauwer, V.; Park, Y.-J.; Moore, G. Seaborne measurements of near infrared water-leaving reflectance: The similarity spectrum for turbid waters. Limnol. Oceanogr. 2006, 51, 1167-1179. [CrossRef]

31. Doxaran, D.; Castaing, P.; Lavender, S. Monitoring the maximum turbidity zone and detecting fine-scale turbidity features in the Gironde estuary using high spatial resolution satellite sensor (SPOT HRV, Landsat ETM+) data. Int. J. Remote Sens. 2006, 27, 2303-2321. [CrossRef]

32. Koponen, S.; Attila, J.; Pulliainen, J.; Kallio, K.; Pyhälahti, T.; Lindfors, A.; Rasmus, K.; Hallikainen, M. A case study of airborne and satellite remote sensing of a spring bloom event in the Gulf of Finland. Cont. Shelf Res. 2007, 27, 228-244. [CrossRef]

33. Nechad, B.; Ruddick, K.G.; Park, Y. Calibration and validation of a generic multisensor algorithm for mapping of total suspended matter in turbid waters. Remote Sens. Environ. 2010, 114, 854-866. [CrossRef]

34. Svab, E.; Tyler, A.; Preston, T.; Présing, M.; Balogh, K.V. Characterizing the spectral reflectance of algae in lake waters with high suspended sediment concentrations. Int. J. Remote Sens. 2005, 26, 919-928. [CrossRef]

35. Villar, R.E.; Martinez, J.-M.; Arrmijos, E.; Espinoza, J.-C.; Filizola, N.; Dos Santos, A.; Willems, B.; Fraizy, P.; Santini, W.; Vauchel, P. Spatio-temporal monitoring of suspended sediments in the Solimões River (2000-2014). Comptes Rendus Geosci. 2018, 350, 4-12. [CrossRef]

36. Martinez, J.-M.; Espinoza-Villar, R.; Arrmijos, E.; Moreira, L.S. The optical properties of river and floodplain waters in the Amazon River Basin: Implications for satellite-based measurements of suspended particulate matter. J. Geophys. Res. Earth Surf. 2015, 120, 1274-1287. [CrossRef]

37. Ritchie, J.C.; Schiebe, F.R.; McHenry, J.R. Remote sensing of suspended sediments in surface waters. Photogramm. Remote Sens. 1976, 42, 1539-1545.

38. Kutser, T.; Paavel, B.; Verpoorter, C.; Ligi, M.; Soomets, T.; Toming, K.; Casal, G. Remote sensing of black lakes and using $810 \mathrm{~nm}$ reflectance peak for retrieving water quality parameters of optically complex waters. Remote Sens. 2016, 8, 497. [CrossRef]

39. Kallio, K.; Kutser, T.; Hannonen, T.; Koponen, S.; Pulliainen, J.; Vepsäläinen, J.; Pyhälahti, T. Retrieval of water quality from airborne imaging spectrometry of various lake types in different seasons. Sci. Total Environ. 2001, 268, 59-77. [CrossRef]

40. Giardino, C.; Brando, V.; Gege, P.; Pinnel, N.; Hochberg, E.; Knaeps, E.; Reusen, I.; Doerffer, R.; Bresciani, M.; Braga, F.; et al. Imaging spectrometry of inland and coastal waters: State of the art, achievements and perspectives. Surv. Geophys. 2018, 40, 401-429. [CrossRef]

41. Dekker, A.; Vos, R.J.; Peters, S.W.M. Analytical algorithms for lake water TSM estimation for retrospective analyses of TM and SPOT sensor data. Int. J. Remote Sens. 2002, 23, 15-35. [CrossRef]

42. Martins, V.S.; Barbosa, C.C.F.; de Carvalho, L.A.S.; Jorge, D.; Lobo, F.D.L.; Novo, E. Assessment of atmospheric correction methods for sentinel-2 MSI images applied to Amazon Floodplain Lakes. Remote Sens. 2017, 9 , 322. [CrossRef]

43. Borges, H.D.; Cicerelli, R.E.; De Almeida, T.; Roig, H.L.; Olivetti, D. Monitoring cyanobacteria occurrence in freshwater reservoirs using semi-analytical algorithms and orbital remote sensing. Mar. Freshw. Res. 2020, 71, 569. [CrossRef] 
44. Da Costa, N.Y.M.; Boaventura, G.R.; Mulholland, D.S.; Araújo, D.F.; Moreira, R.C.A.; Faial, K.C.F.; Bomfim, E.D.O. Biogeochemical mechanisms controlling trophic state and micropollutant concentrations in a tropical artificial lake. Environ. Earth Sci. 2016, 75. [CrossRef]

45. Sodré, F.F.; Sampaio, T.R. Development and application of a SPE-LC-QTOF method for the quantification of micropollutants of emerging concern in drinking waters from the Brazilian capital. Emerg. Contam. 2020, 6, 72-81. [CrossRef]

46. Roig, H.L.; Garnier, J.; Ianniruberto, M.; Minoti, R.; Koide, S. Estudo multidisciplinar do estado físico do lago paranoá: Topo-batimetria, qualidade dos sedimentos e balanço hídrico. In Relatório Técnico. Convênio; Universidade de Brasília: Brasília, Brazil, 2019. (In Portuguese)

C 2020 by the authors. Licensee MDPI, Basel, Switzerland. This article is an open access article distributed under the terms and conditions of the Creative Commons Attribution (CC BY) license (http://creativecommons.org/licenses/by/4.0/). 